\title{
Human Development Index of the maternal country of origin and its relationship with maternal near miss: A systematic review of the literature
}

Santiago García-Tizón Larroca ${ }^{1 *}$, Francisco Amor Valera ${ }^{1}$, Esther Ayuso Herrera ${ }^{1}$, Ignacio Cueto Hernandez', Yolanda Cuñarro Lopez ${ }^{1}$ and Juan De Leon-Luis ${ }^{1,2}$

\begin{abstract}
Background: The reduction in maternal mortality worldwide has increased the interest in studying more frequent severe events such as maternal near miss. The Human Development Index is a sociodemographic country-specific variable that includes key human development indicators such as living a long and healthy life, acquiring knowledge, and enjoying a decent standard of living, allowing differentiation between countries. In a globalised environment, it is necessary to study whether the Human Development Index of each patient's country of origin can be associated with the maternal near-miss rate and thus classify the risk of maternal morbidity and mortality.

Methods: A systematic review of the literature published between 2008 and 2019 was conducted, including all articles that reported data about maternal near miss in their sample of pregnant women, in addition to describing the study countries of their sample population. The Human Development Index of the study country, the maternal near-miss rate, the maternal mortality rate, and other maternal-perinatal variables related to morbidity and mortality were used.
\end{abstract}

Results: After the systematic review, eighty two articles from over thirty countries were included, for a total of 3, 699,697 live births, 37,191 near miss cases, and 4029 mortality cases. A statistically significant $(p<0.05)$ inversely proportional relationship was observed between the Human Development Index of the study country and the maternal near-miss and mortality rates. The most common cause of maternal near miss was haemorrhage, with an overall rate of $38.5 \%$, followed by hypertensive disorders of pregnancy $(34.2 \%)$, sepsis $(7.5 \%)$, and other undefined causes (20.9\%).

Conclusions: The Human Development Index of the maternal country of origin is a sociodemographic variable allowing differentiation and classification of the risk of maternal mortality and near miss in pregnant women. The most common cause of maternal near miss published in the literature was haemorrhage.

Trial registration: PROSPERO ID: CRD 42019133464

Keywords: Maternal near miss, Maternal mortality, Human Development Index, Immigrants

\footnotetext{
*Correspondence: gineteca@gmail.com

'Maternal Fetal Medicine, Department of Obstetrics and Gynaecology,

HGUGM, Calle O' Donnell, 48, Planta 0, 28009 Madrid, Spain

Full list of author information is available at the end of the article
}

(c) The Author(s). 2020 Open Access This article is licensed under a Creative Commons Attribution 4.0 International License, which permits use, sharing, adaptation, distribution and reproduction in any medium or format, as long as you give appropriate credit to the original author(s) and the source, provide a link to the Creative Commons licence, and indicate if changes were made. The images or other third party material in this article are included in the article's Creative Commons licence, unless indicated otherwise in a credit line to the material. If material is not included in the article's Creative Commons licence and your intended use is not permitted by statutory regulation or exceeds the permitted use, you will need to obtain permission directly from the copyright holder. To view a copy of this licence, visit http://creativecommons.org/licenses/by/4.0/ The Creative Commons Public Domain Dedication waiver (http://creativecommons.org/publicdomain/zero/1.0/) applies to the data made available in this article, unless otherwise stated in a credit line to the data. 


\section{Background}

Worldwide, over 1500 women die every day due to complications of pregnancy or childbirth. It is possible that most of these deaths could be prevented if the women were in countries other than their countries of origin. Although the Millennium Development Goal of reducing maternal mortality (MM) by 75\% between 1990 and 2015 has not been achieved globally, significant progress has been made; in many countries, maternal health has improved significantly, and the goals for 2030 are to achieve MM rates of less than 70 per 100,000 live births and to increase the proportion of births attended by skilled health personnel [1]. One of the Millennium Development Goals set in 2000 by the member countries of the United Nations is to improve the health of women through multiple interventions, such as promoting access to family planning services and emergency obstetric care by qualified and trained personnel. In this respect, women in low-income countries are especially vulnerable to dying from obstetric causes. The World Health Organization, through its "Global Strategy for Women's, Children's and Adolescents' Health (2016-2030)," is analysing relevant indicators and scores to improve the survival of newborns and pregnant women. Although the world has made substantial progress on these two issues, the decline in maternal and neonatal mortality has recently slowed down. Moreover, in 2017-2019, the Quality of Care Network group supported by the WHO included more countries - such as Ethiopia, Ghana, India, Malawi, Nigeria, Tanzania and Uganda - on its agenda to complete the following tasks:

- Accelerate action by adapting the WHO's standards for improving the quality of maternal and newborn care in health facilities at the country level.

- Foster learning and generate evidence on quality of care through a learning platform.

- Develop and support institutions and mechanisms that will ensure accountability for quality of care by designing a national accountability framework.

Traditionally, the analysis of maternal deaths has been the approach of choice for evaluating women's health and the quality of obstetric care. However, due to the success of modern medicine, such deaths have become very rare in developed countries, which has led to an increased interest in analysing so-called "near miss" events. The World Health Organization defines a maternal near miss (MNM) as "a woman who nearly died but survived a complication that occurred during pregnancy, childbirth or within forty-two days of termination of pregnancy". A MNM is also assumed to be a better indicator than MM alone when designing, monitoring, followingup and evaluating safe motherhood programmes [2].
Year after year, increasingly more authors are interested in publishing MNM events that occur in their countries, and it is necessary to analyse morbidity and mortality data over the past decade to compare situations in different countries.

Haemorrhage, hypertensive disorders of pregnancy, and infections stand out as the direct causes of more than $70 \%$ of both MNM and mortality. In all these cases, the lack of care or access to care, the high cost of health care or its poor quality, and the variation among different countries results in 1 million maternal orphans every year, and these children are also more likely to die during the years following their mother's death.

For years, gross national income per capita has been used to weigh differences among countries; however, in the 1990s, the WHO introduced the Human Development Index (HDI) as a sociodemographic variable to help differentiate countries, thus avoiding reliance on the purely economic value of each nation and trying to classify the world population in homogeneous groups through more comprehensive indicators.

This index has helped the WHO to establish different strategies to end preventable maternal morbidity and mortality; its use is increasingly widespread in the medical literature, where a very high HDI is typical of countries with more resources. Tuncalp is the first author to relate the HDI of the maternal country of origin to severe maternal outcomes such as MNM and MM with data from countries in Africa, Asia, Latin America, and the Middle East. That author describes a significant relationship between mothers from countries with medium and low HDIs; women in those countries are shown to have a risk of maternal complications that is 2-3 times higher than for women from countries with high HDIs [3].

Using the HDI of pregnant women from other countries and assessing the influence of HDI on maternal-perinatal health in our country, Spain, a previous study conducted by our team [4] observed an increased risk of adverse maternal-perinatal events in pregnant women from lowHDI countries compared to women originating from countries with higher HDIs. Similarly, Luque-Fernandez et al. [5], analysing the trend of stillbirth in Spain, showed an increased risk of stillbirth, approximately three times higher, in pregnant women from low-HDI countries. For both authors, incorporating HDI improves the characterisation of the maternal socio-economic level by introducing the HDI of the maternal country of origin and maternal educational attainment to population analysis, producing a fuller analysis compared to those studies that only include the country of origin of immigrant pregnant women.

In this study, we will consider the HDI of the place of publication (as a proxy measure like that used in the study on immigration) and determine the relationship with adverse maternal-perinatal outcomes. 
The aim of this study is to conduct a systematic review of the articles published over the last decade reporting severe acute maternal morbidity. We use as a reference the HDI of the country where the study was conducted-which directly reflects the HDI of its population of pregnant women-to analyse its relationship with relevant adverse maternal-perinatal outcomes during pregnancy, childbirth, and the postpartum period, such as MNM and MM.

\section{Methods}

Protocol, eligibility criteria, information sources and search strategies

This review was performed according to an a-prioridesigned protocol recommended for systematic reviews. PRISMA [6] and MOOSE guidelines were followed [7]. The study was registered in the PROSPERO database (registration number: CRD 42019133464). The systematic literature search was conducted in two electronic databases, PubMed/MEDLINE and EMBASE, utilising combinations of the relevant medical subjects by MeSH terms with the following keywords: "near miss" or "morbidity" and "pregnancy" or "mothers" or "pregnancy outcome". The search period was between 17/02/2008 and 17/02/ 2019. A reference database (EndNote X7, Thomson Reuters) was used to incorporate all references.

The inclusion criteria were as follows:

- studies published between 17/02/2008 and 17/02/2019;

- studies conducted with humans;

- studies in English, both the abstract and the main text; and

- studies that included MNM analysis in their study population.

The exclusion criteria were as follows:

- studies with scarce information about the study population, such as country of origin, or studies investigating specific ethnic, racial, or immigrant groups;

- published articles that did not report data on MNM or those on maternal morbidity events not meeting MNM criteria according to the WHO;

- systematic reviews, expert opinions, and intervention studies without quantitative data about the MNM rate; and

- studies conducted on the same patient cohort. In these cases, we selected the most up-to-date patient cohorts and excluded secondary analysis studies on the same sample.

\section{Study selection}

Titles and abstracts of the search results were screened by two researchers independently (SGTL and FAV). If the title and abstract did not provide useful information for the review or was irrelevant, the articles were eliminated from the analysis. Potentially eligible studies were assessed in full-text format. Any disagreement on the eligibility of studies was resolved through discussion and joint assessment until consensus was reached between the two researchers.

\section{Data collection and data items}

Data were extracted using an appraised extraction form. Each reviewer collected the data independently, and discrepancies between them were resolved by the two authors checking the study against the form. The review authors were not blinded to the journal or author details. Extracted data included the name of the first author and year of publication, first and last year of the study, study period, country or countries where the study was conducted, HDI group to which the study country belongs, and the HDI score of the study country.

The HDI is a summary measure of a country's average level of achievement in the following major dimensions of human development: living a long and healthy life, being educated, and having a decent standard of living. Life expectancy serves as an indicator of the health dimension; standard of living is measured in terms of gross national income per capita; and education level is evaluated as the average number of years of schooling among adults aged twenty-five years and older and expected number of years of schooling among children [8].

A country obtains a higher HDI score when its population has a higher life expectancy, education level, and gross national income (GNI) per capita; these scores are reported within the annual Human Development Report published by the United Nations Development Programme (UNDP) [9]. The UNDP divides countries into four broad categories of human development: group 1 (very high $\mathrm{HDI}$ ), group 2 (high $\mathrm{HDI}$ ), group 3 (medium HDI), and group 4 (low HDI) based on the numerical score obtained, with a minimum of 0 and a maximum of 1 .

Other maternal-perinatal variables included in the study were type of study (single- or multi-centre), study design, total number of live births (LBs), number of MNM events in the study, rate of MNM/1000 LBs, number of maternal mortality events, rate of $M M / 100$, $000 \mathrm{LBs}$, percentage of MNM due to haemorrhage, percentage of MNM due to hypertensive disorders of pregnancy, percentage of MNM due to sepsis, percentage of MNM due to other causes, MNM in the immigrant population, MNM by ethnic group, maternal age at MNM, percentage of primiparous mothers in the MNM group, parity in MNM, percentage of births $<37$ weeks gestation in the MNM group, caesarean section rate in the MNM group, and neonatal near miss. 
In the case of multicountry studies, the average HDI score given by the HDI scores of all included countries was calculated.

After data collection, the data were ordered according to the publication year.

\section{Risk of bias assessment and statistical analysis}

The risk of bias was assessed independently by both authors, who determined the adequacy of compliance with the inclusion criteria. The items assessed were correct description of MNM cases, complete reporting of proportion and type of near miss in the case group, and adequate description of the country or countries where the study was carried out. We tried to choose strict eligibility criteria to achieve a good number of studies that were as homogeneous as possible and thereby extract concrete and valid conclusions.

The quality of the evidence of the studies included was assessed according to the Grade of Evidence Working Group Criteria [10].

Statistical analyses were carried out using STATA, version 13.1 (Stata Corp., College Station, TX, USA) in its default settings. The results are expressed as rates (\%) for dichotomous variables, and we calculated 95\% confidence intervals (95\% CIs). We tried to perform a quantitative synthesis with pooled relative risks and 95\% confidence intervals $(95 \% \mathrm{CI})$, but a meta-analysis was not feasible given the lack of a control group and the heterogeneity of the available studies.

\section{Results}

Figure 1 describes the workflow process. As shown, the initial search identified 4842 articles in the databases. After screening and applying the eligibility and exclusion criteria in the final phase of the records, eighty-two articles were selected. A total of 3,699,697 LBs, 37,191 near miss cases and 4029 mortality cases were reported, representing the population analysed in this systematic review.

Table 1 describes the results obtained in each study for the different variables analysed in the review. Over $90 \%$ of the studies were led by different authors; among those who led in publishing, the author who published the most studies in the period included in this analysis of MNM was Jayaratnam, with four. Of all the articles, sixty-two (75.6\%) have been published since 2014, and the study by Okusanya et al. [53] (reference) included

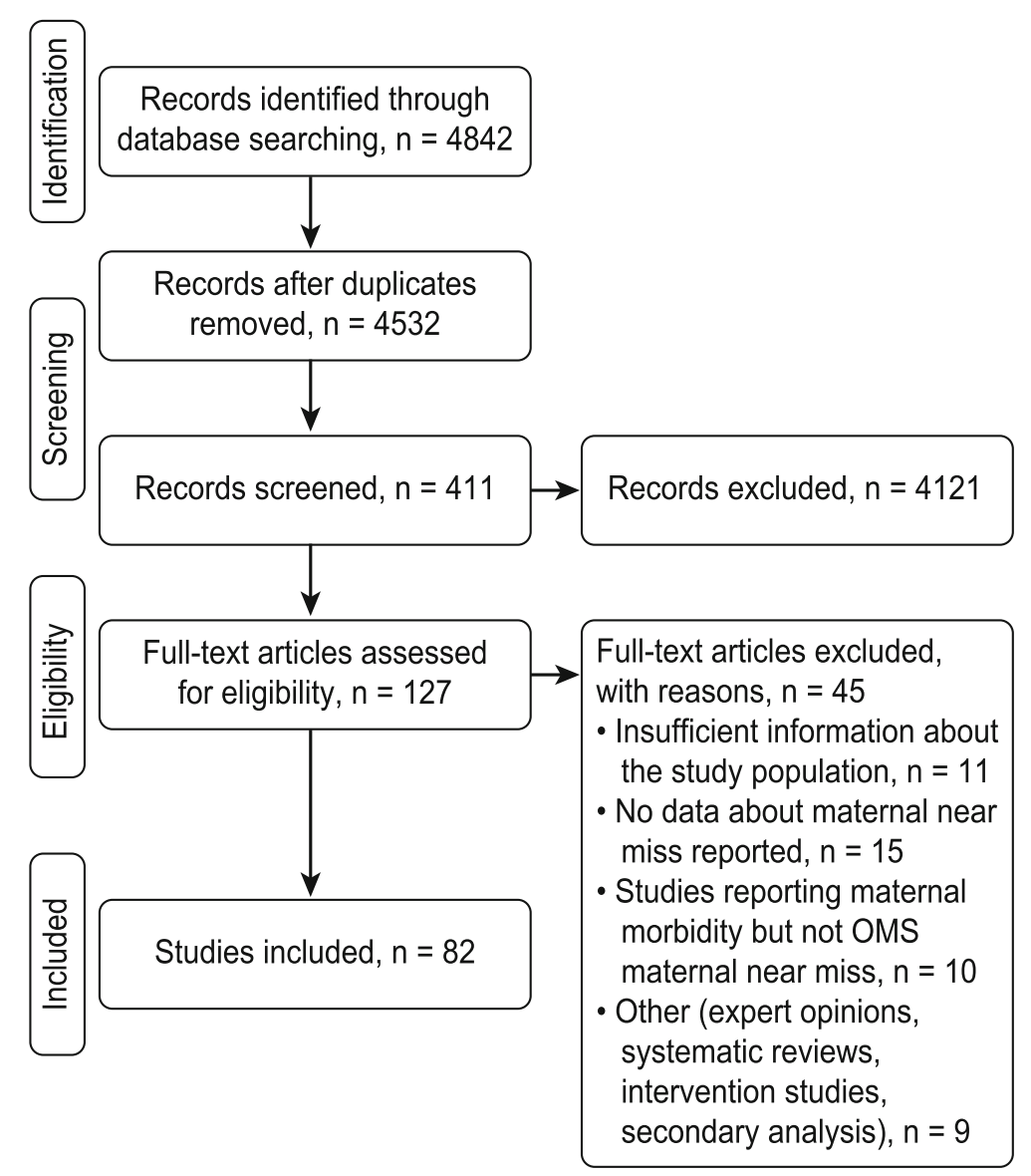

Fig. 1 Work flow process 


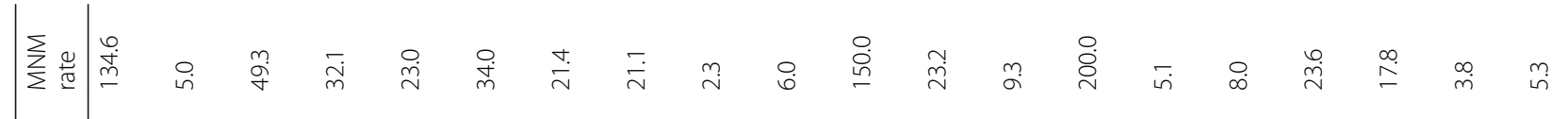

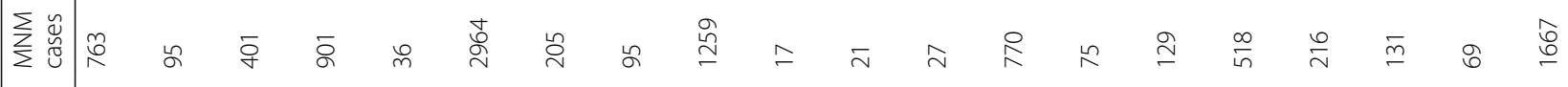

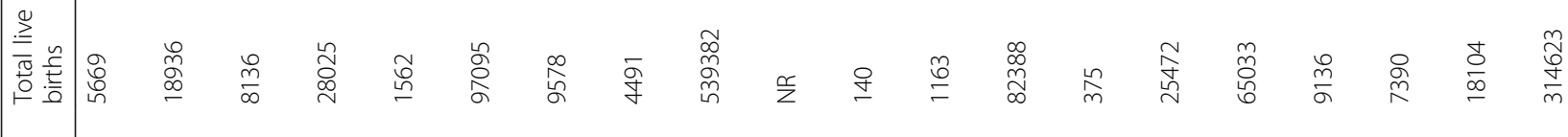

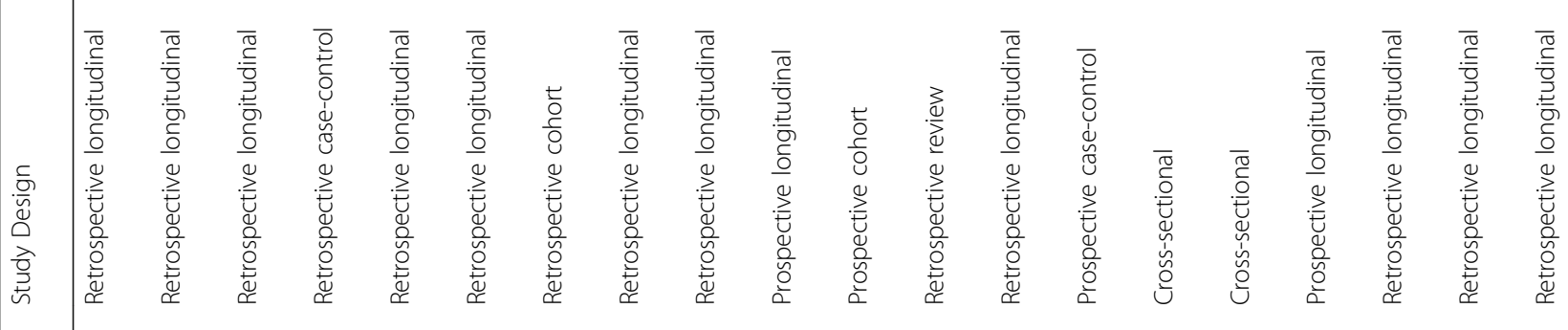

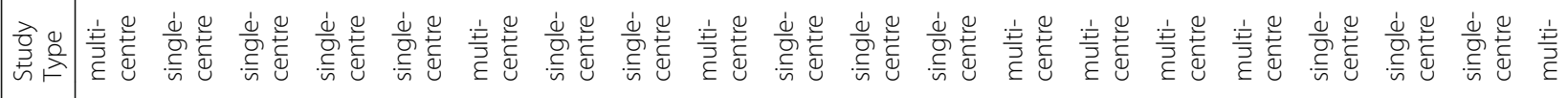

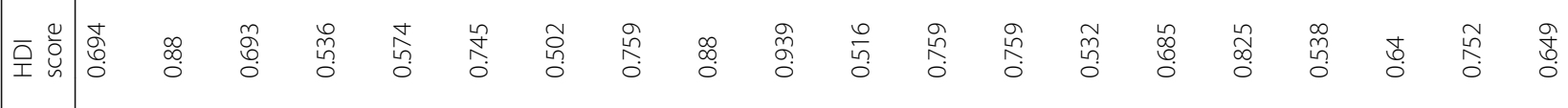

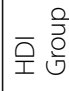
은

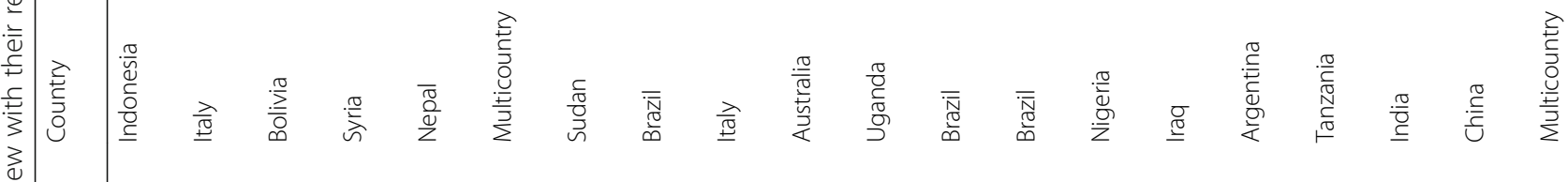

范离 产

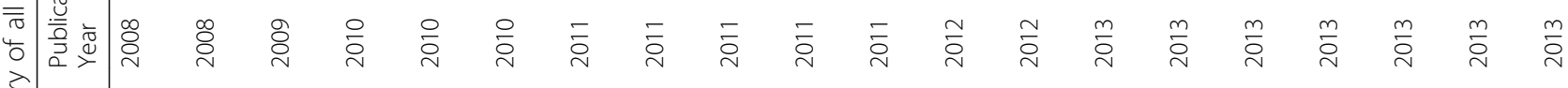

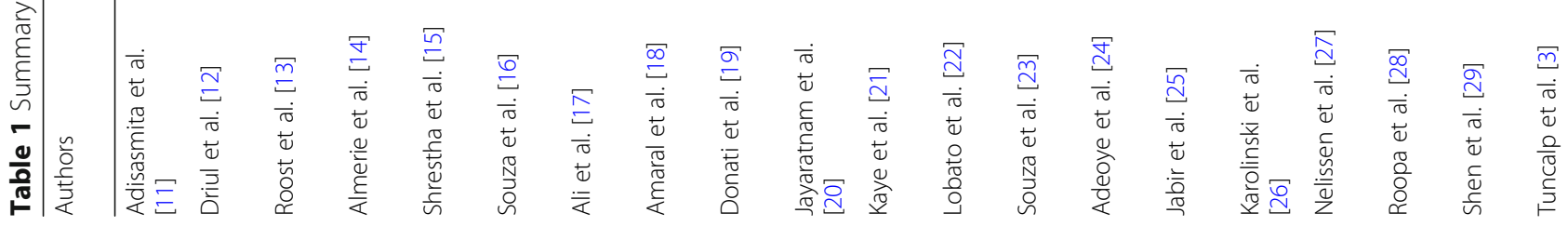




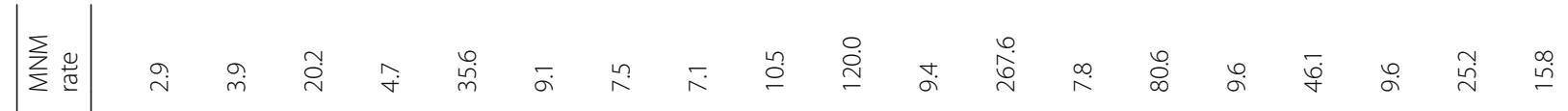

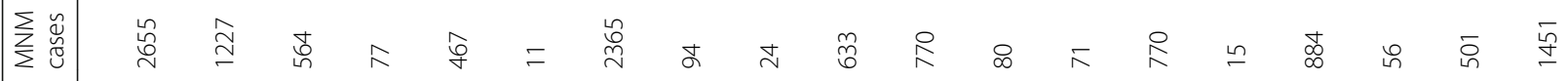

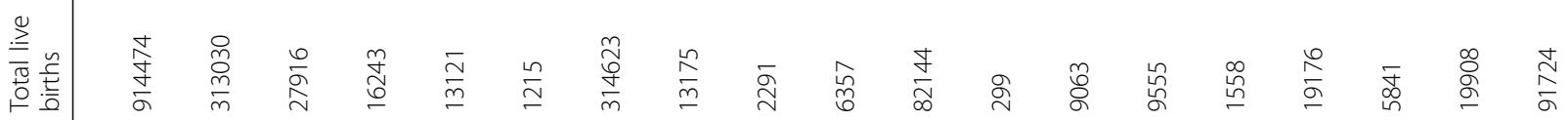

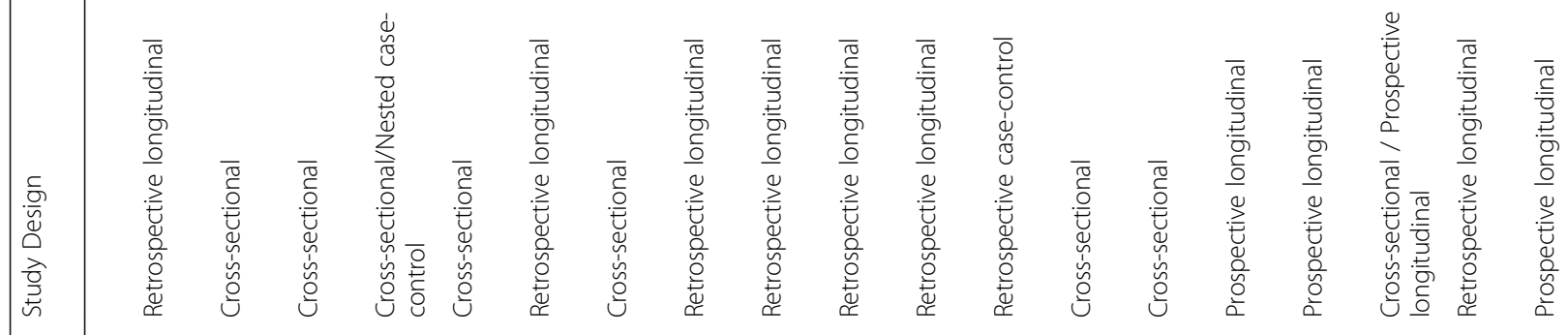

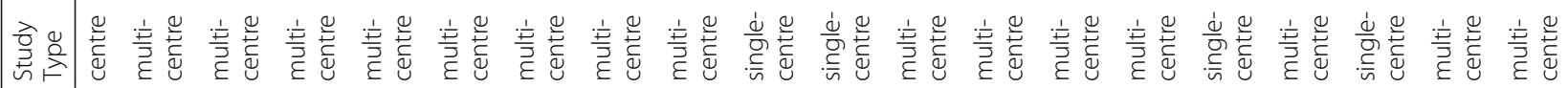

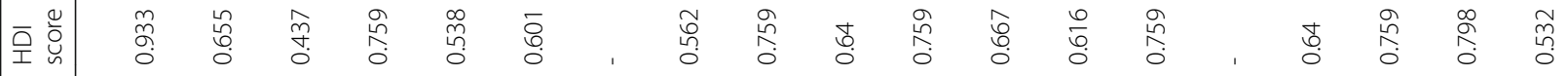

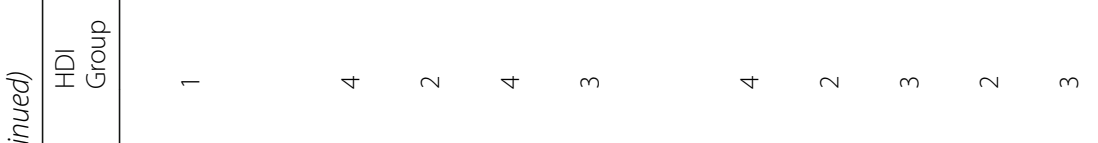




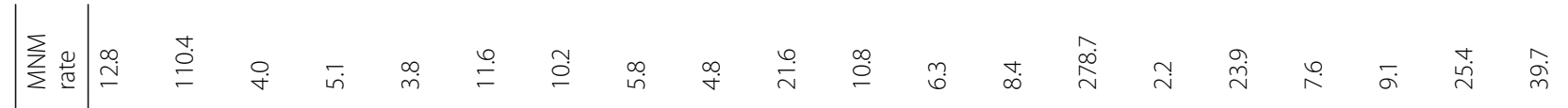

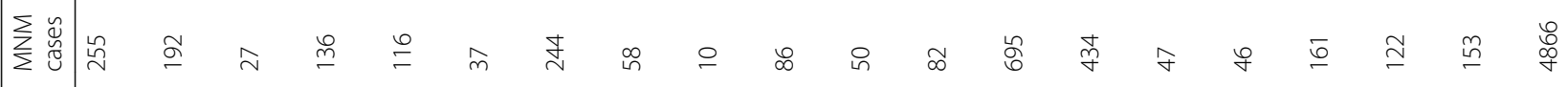

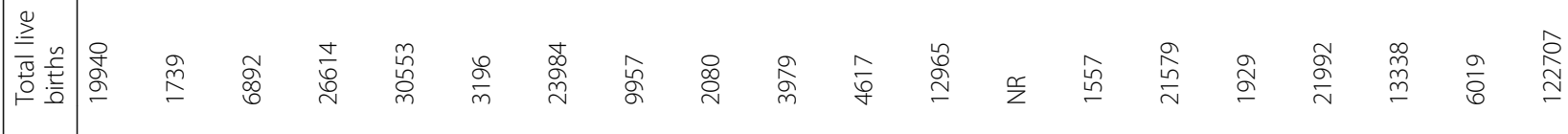

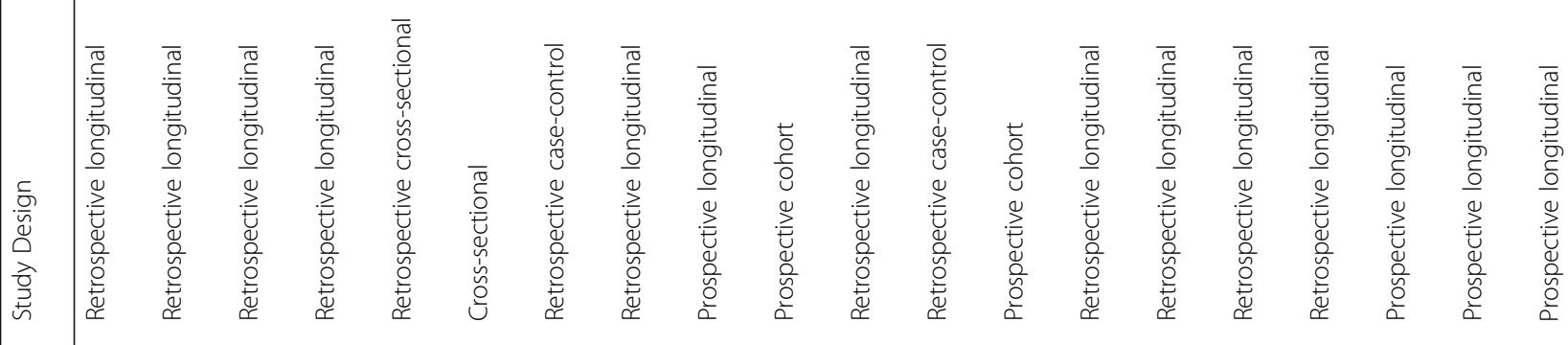

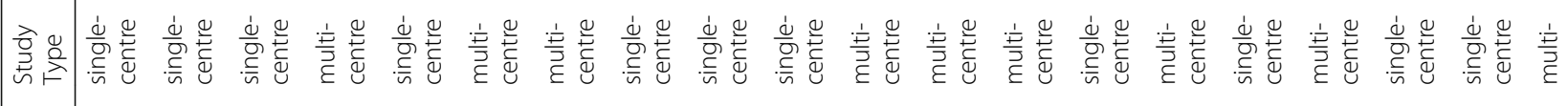

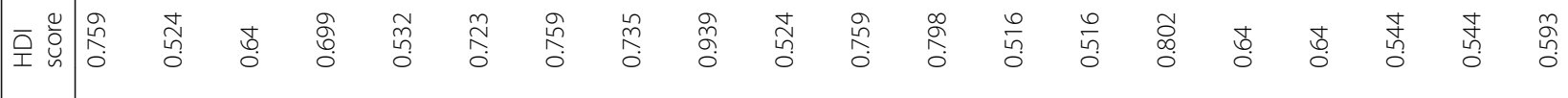

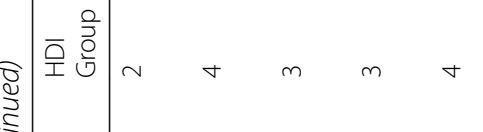

\section{(1)

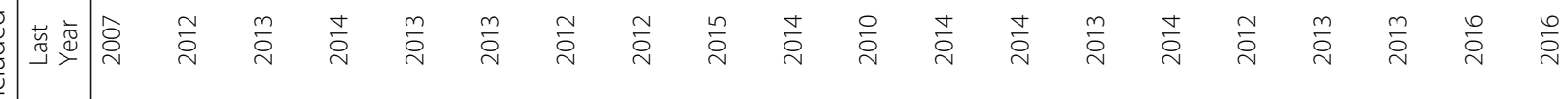

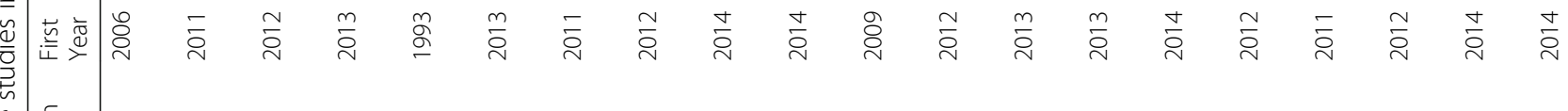

京

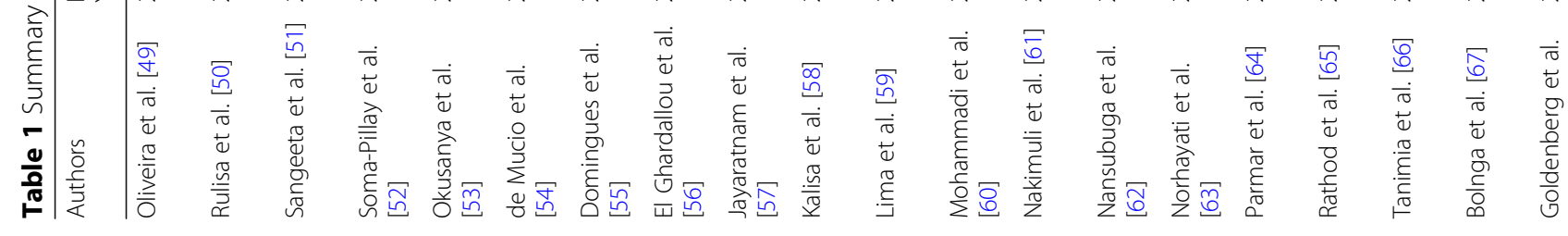




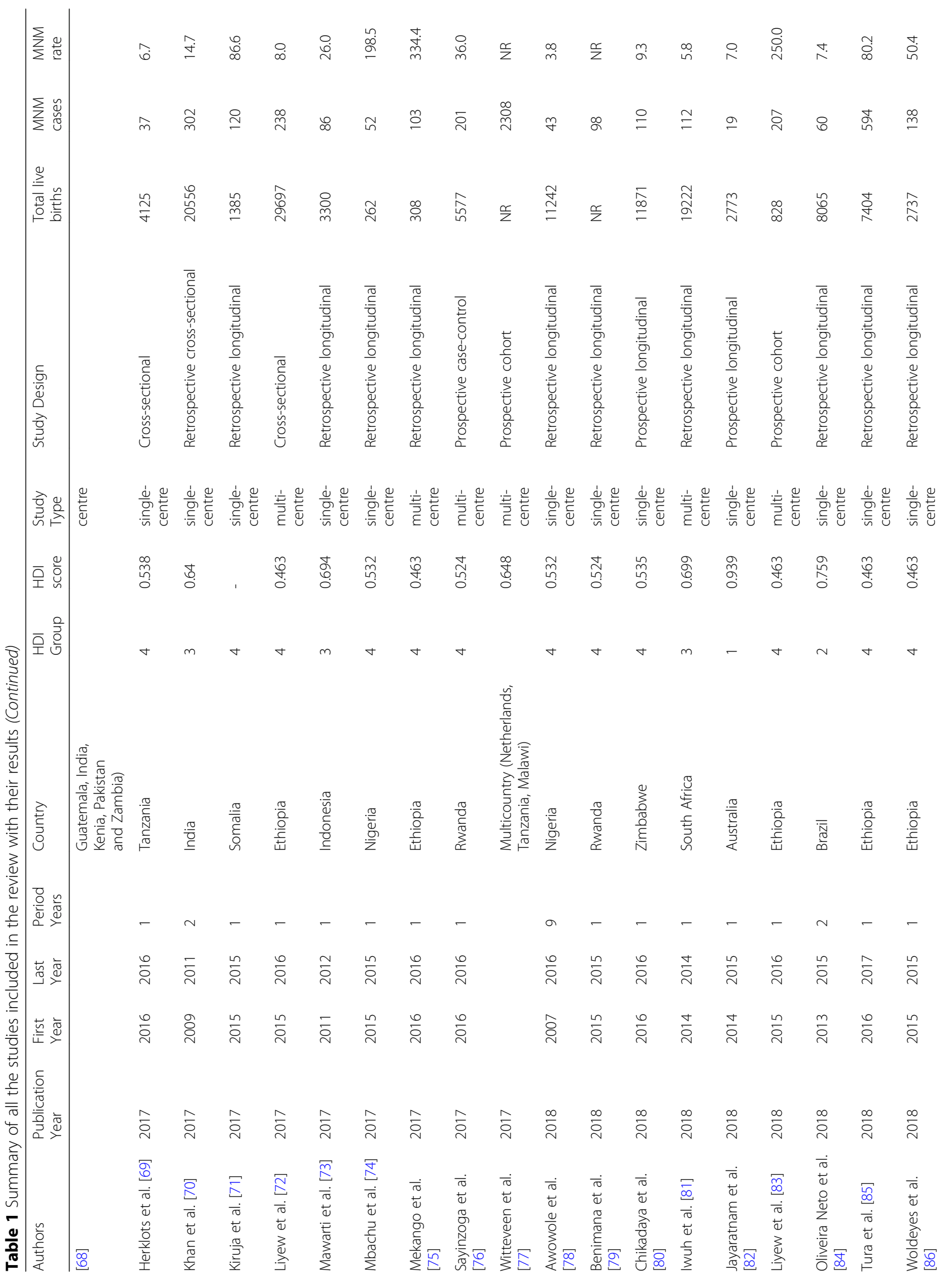




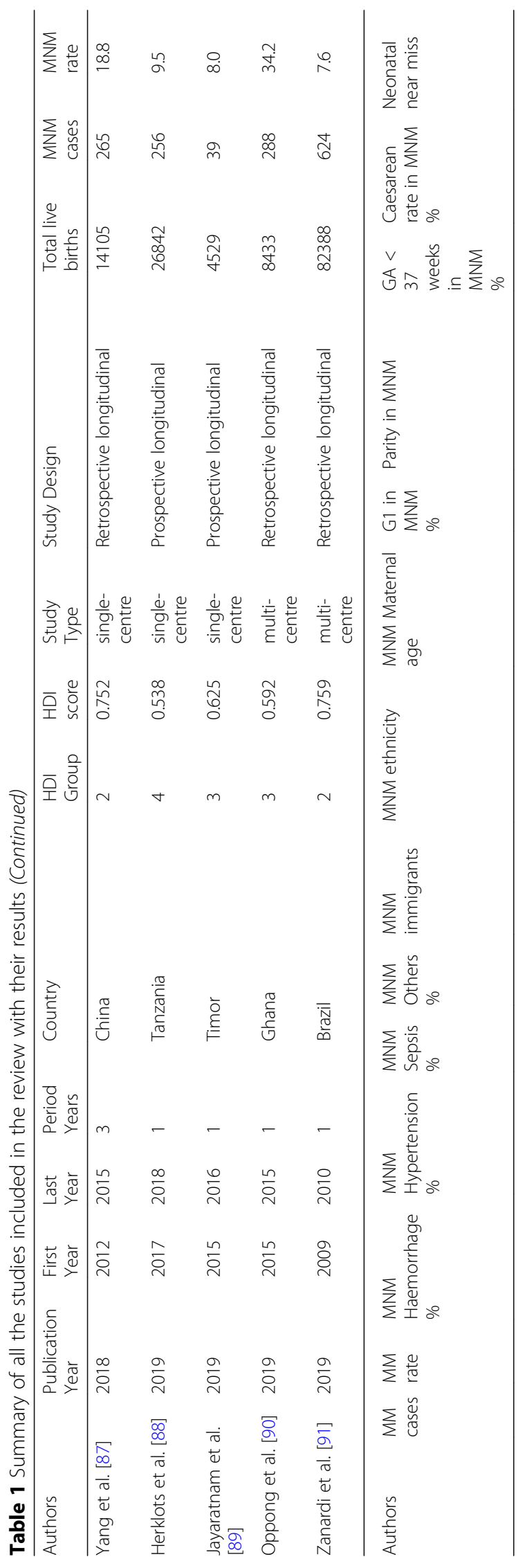




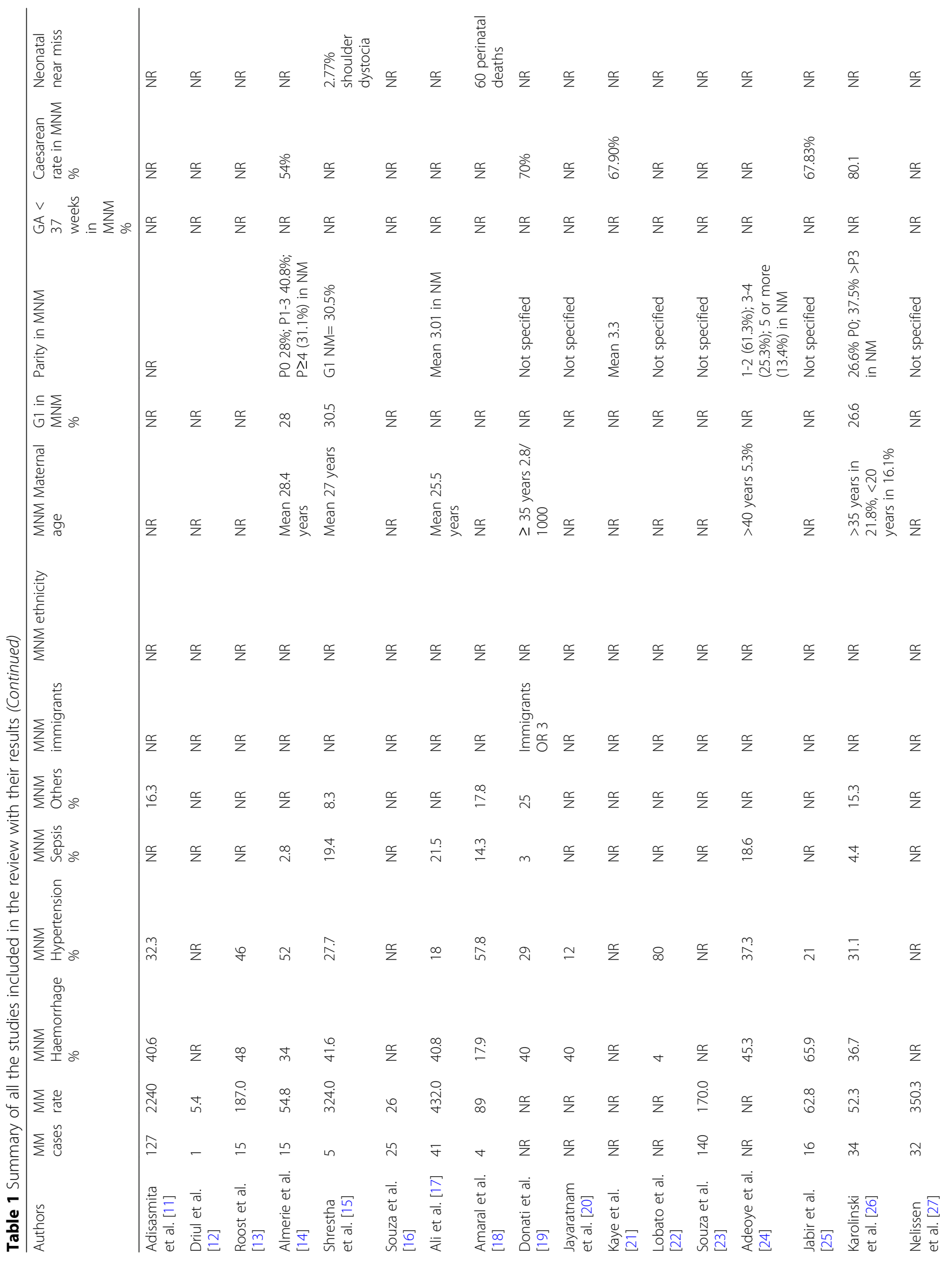




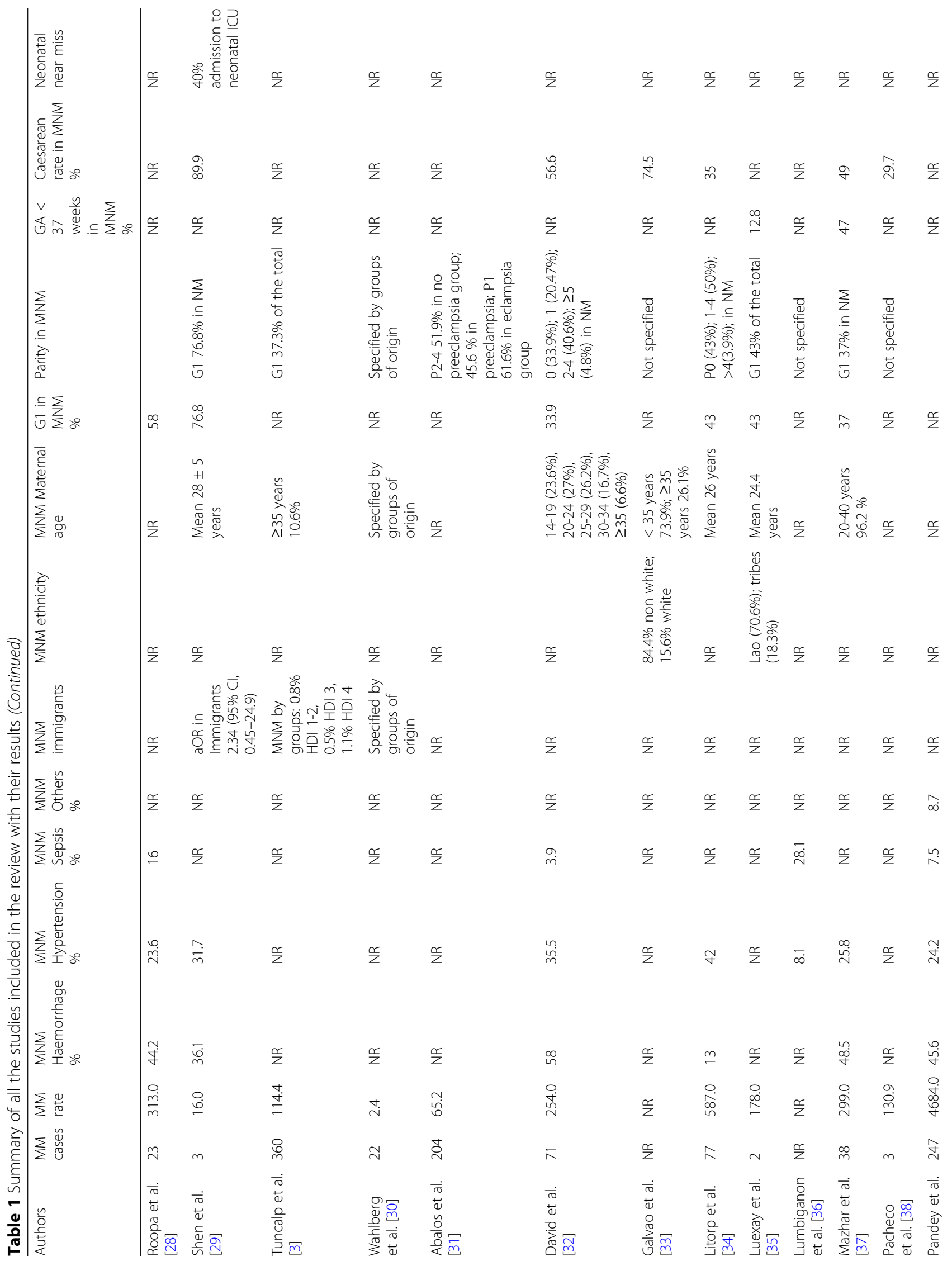


García-Tizón Larroca et al. BMC Pregnancy and Childbirth

(2020) 20:224

Page 12 of 24

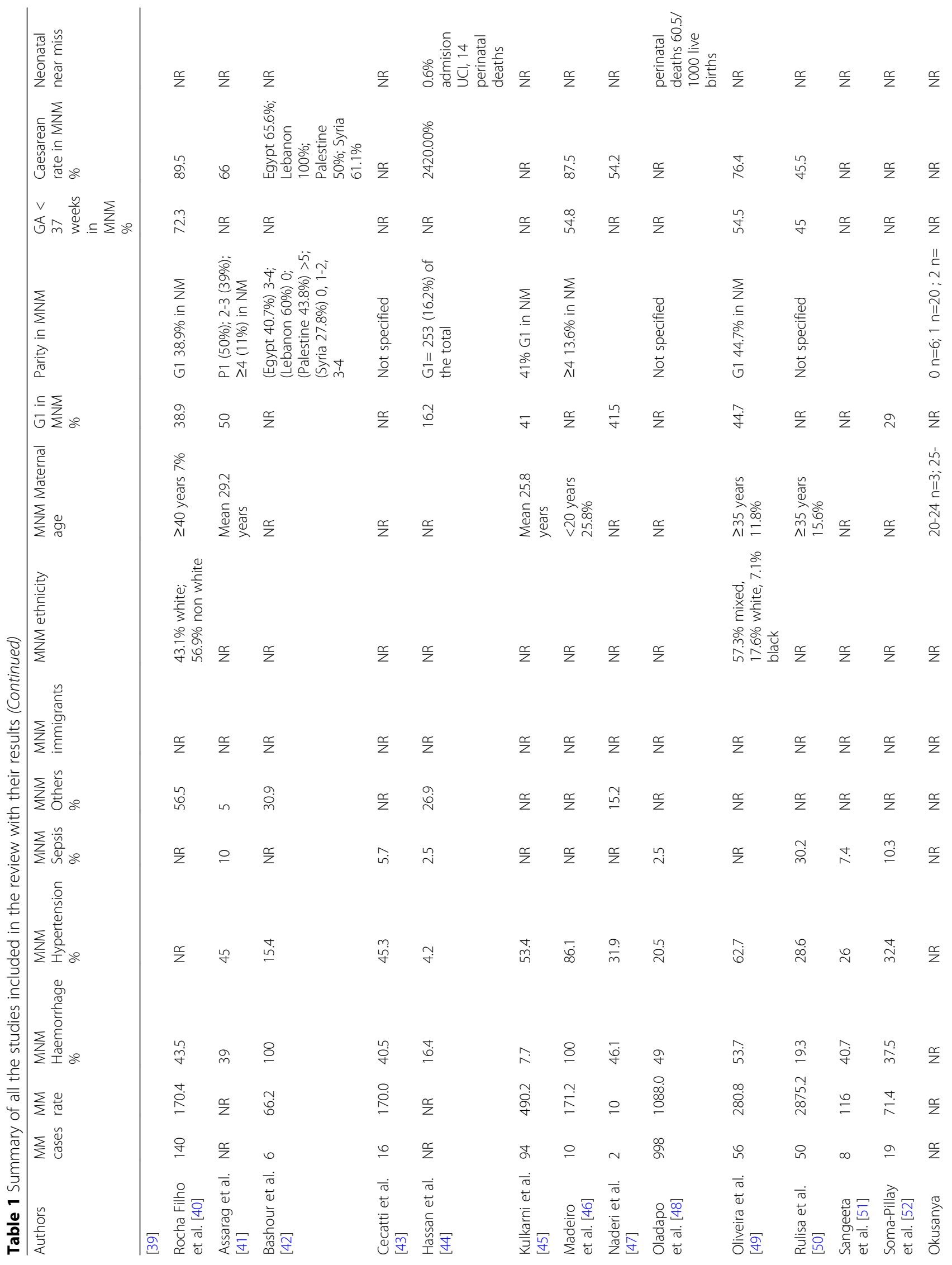




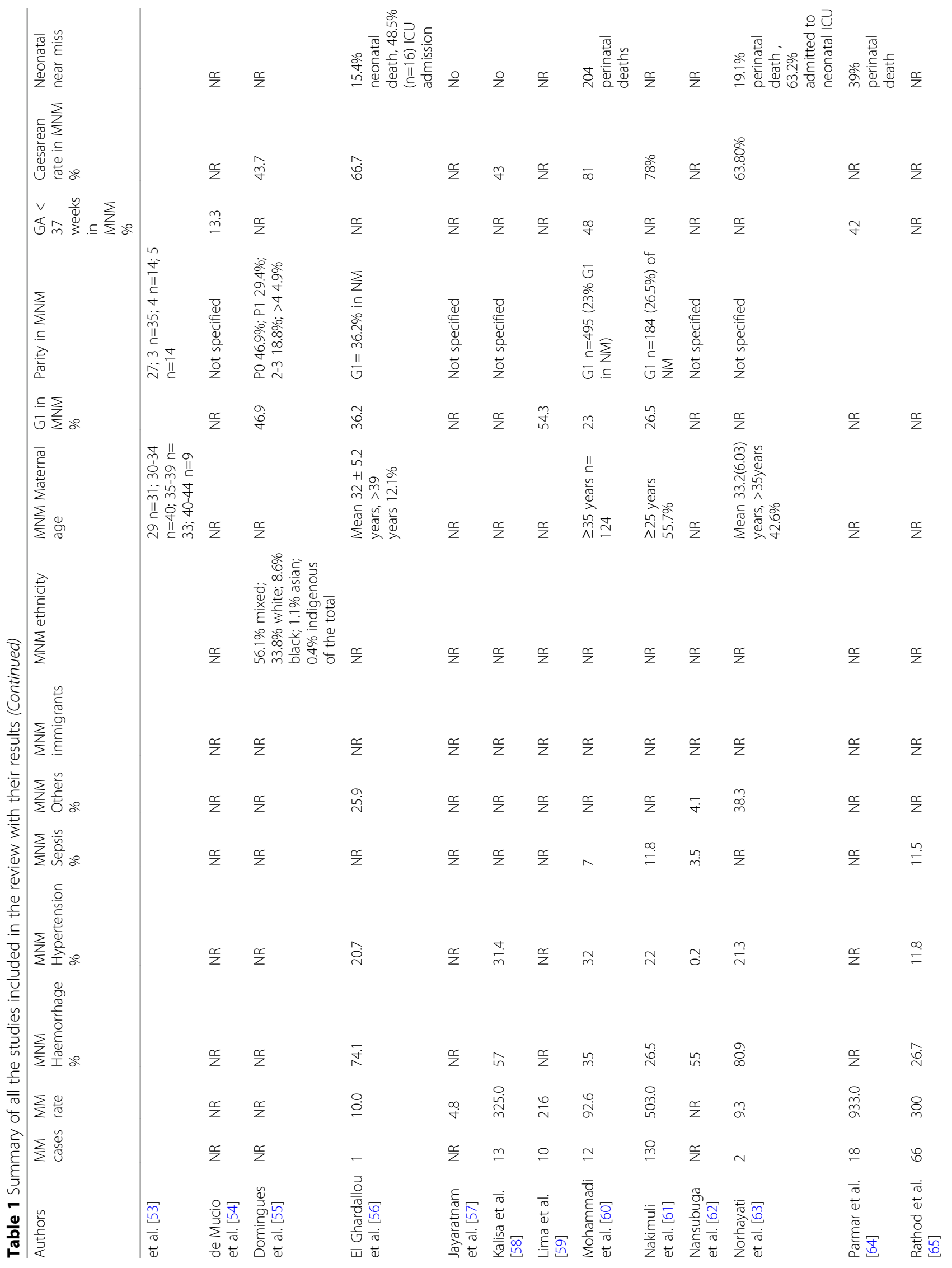




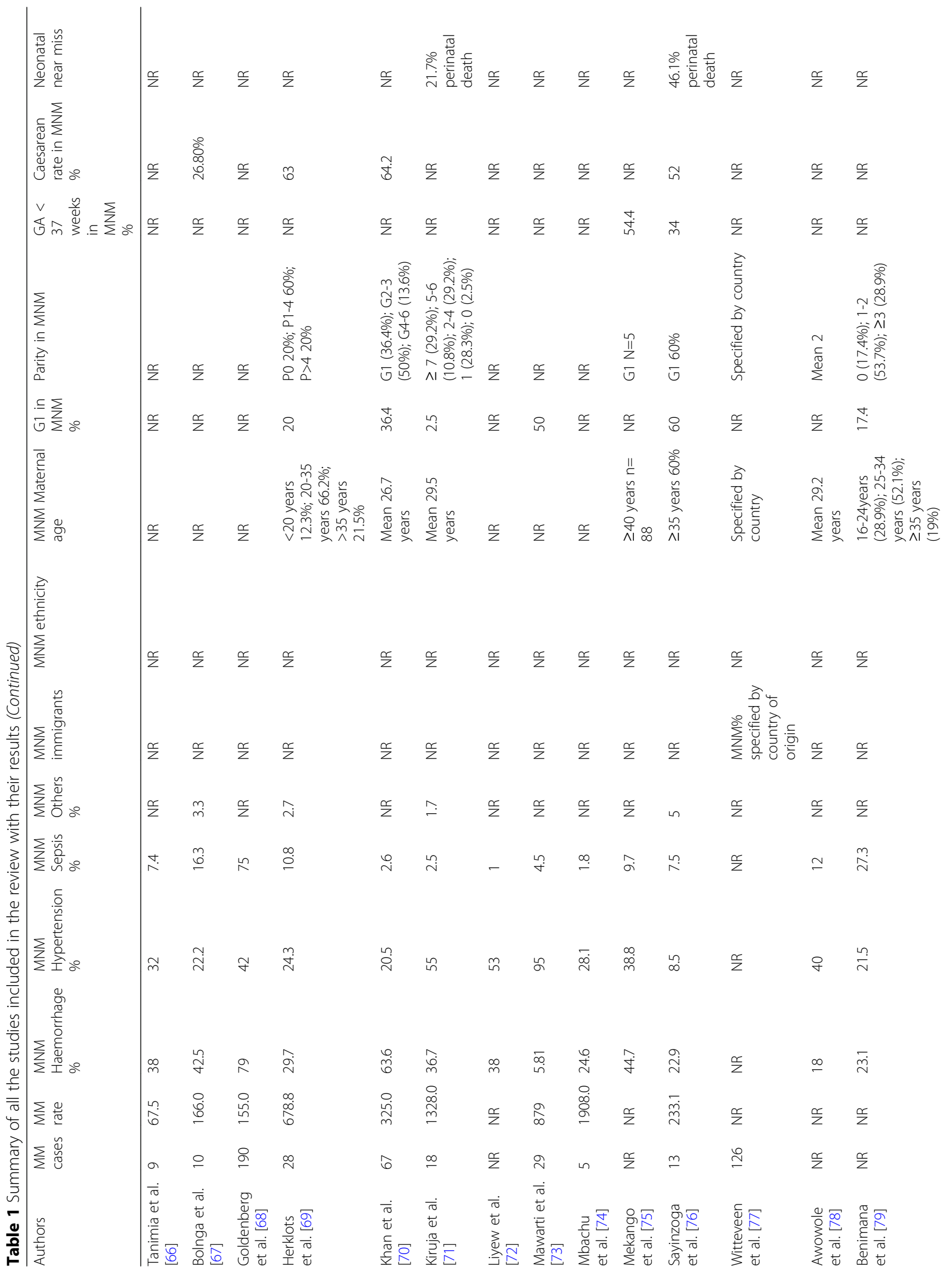




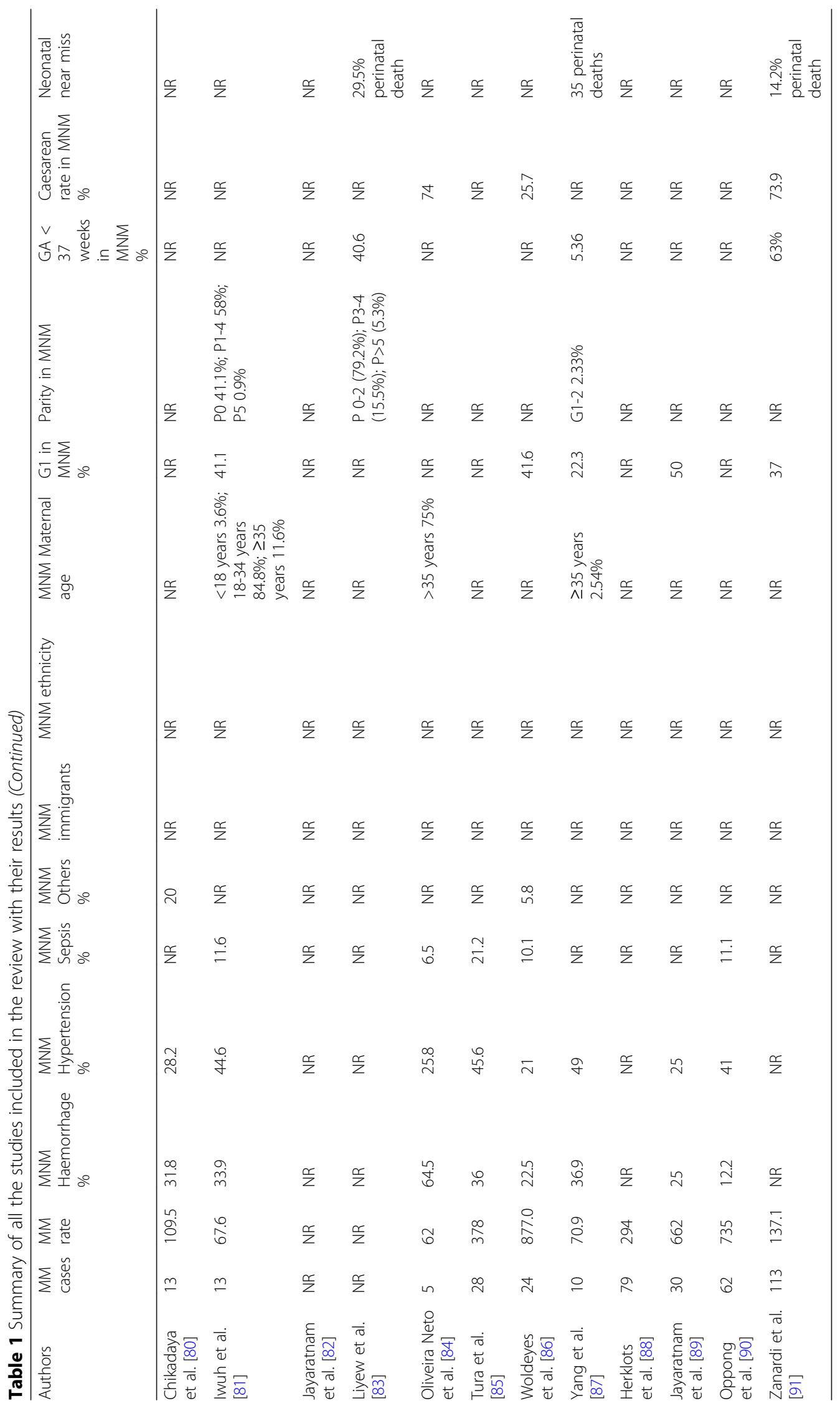


the longest period of data collection, at twenty years. Over $70 \%$ of the studies had a follow-up design with retrospective data collection/analysis.

Looking at single-country studies, over thirty-three countries were represented, and seven studies were conducted with populations from several countries; Brazil published more studies than any other country, with thirteen (15.4\%), followed by India, with six (7.1\%), and Nigeria and Ethiopia, with five each (6\%). Regarding the number of studies classified by HDI group, seven belonged to group 1 , nineteen to group 2 , eighteen to group 3 , and twenty-nine to group 4 . In only three studies, the HDI score could not be obtained because of the lack of data provided regarding the study country.

Regarding the MM rate, the median was 175 deaths per $100,000 / \mathrm{LBs}$, with six studies reporting a rate above 1000; in relation to the MNM rate, the median was 11 events per $1000 \mathrm{LBs}$, with nine studies reporting a rate above 100. Regarding MNM, the average of the overall percentage of publications reported the cause to be haemorrhage (38.5\%), hypertensive disorders of pregnancy (34.2\%), sepsis (7.5\%), and other causes (20.9\%).

In relation to gestational data, the mean percentage of primiparous women in the total cases of MNM published was $37 \%$. The mean percentage of premature births in the MNM cases was $38 \%$. The mean percentage of caesarean sections in the MNM cases reported in the twenty-eight articles that reported these data was $57.2 \%$.

Of all the articles included in the review, only sixteen presented data on adverse neonatal outcomes; the most commonly described complication was perinatal death, reported in twelve articles.

Finally, 4/82 articles referred to the differential analysis of near-miss ratios in immigrants, and $16 / 82$ provided data on perinatal mortality or morbidity (near miss) in their results.

Figures 2 and 3 show the exponential trend relationship between the HDI score of the study population and the MNM and MM rates. In both, an inversely proportional relationship between the two variables was shown; higher MNM rates and higher MM rates were observed for study countries with lower HDI scores, significantly in both cases:

- Average rate of MNM/country $=331.71 \mathrm{e}^{-4.572 \text { country }}$ HDI per 1000 live births $\left(\mathrm{R}^{2}=0.2251 ; p=0.001\right)$

- Average rate of $\mathrm{MM} /$ country $=47290 \mathrm{e}^{-8.663 \text { country }}$ HDI $\mathrm{n}$ per 100,000 live births $\left(\mathrm{R}^{2}=0.4304 ; p=\right.$ $0.038)$

In addition, to provide more detail in these figures, $\mathrm{Ta}$ bles 2 and 3 show the MNM and MM rates, respectively, weighted by the number of LBs according to the HDI group of the study population. The articles whose study

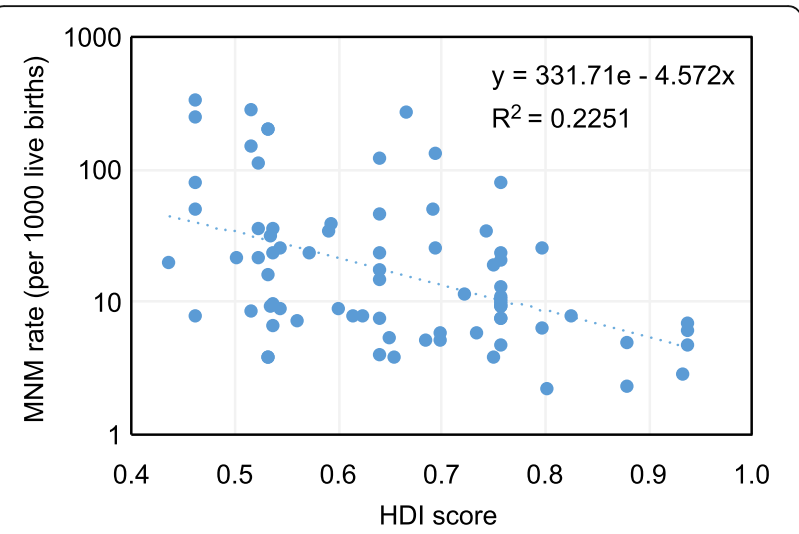

Fig. 2 Relationship between HDI score and MNM rate

population belonged to HDI group 1 showed the lowest MNM and MM rates compared to the rest of the groups. Those whose study population belonged to HDI group 3 had the highest MNM rate, 7.6 times higher than that of HDI group 1. Studies whose population was classified as HDI group 4 had the highest MM rate, 98.4 times higher than that of HDI group 1. It should be noted in these tables that the MNM rate for group 4 was lower than that for HDI group 3.

The proportion of each cause of MNM published in each study is shown in Figure 4. This same figure reflects the overall proportions of each type of MNM. The most common cause of MNM in the set of studies selected in this review was haemorrhage, occurring in $38.5 \%$ (95\% CI, 37.7-39.2) of all cases.

Concerning haemorrhagic causes of MNM, the study by Lobato et al. [22] reported the lowest proportion of this complication, with $3.7 \%$, compared to the study by Madeiro et al. [46], which reported the highest percentage of haemorrhagic causes of MNM, 100\% of total cases in their sample.

Regarding hypertensive disorders as a cause of MNM, the studies by Lobato et al. [22], Madeiro et al. [46], and Mawarti et al. [73] predominantly include populations of

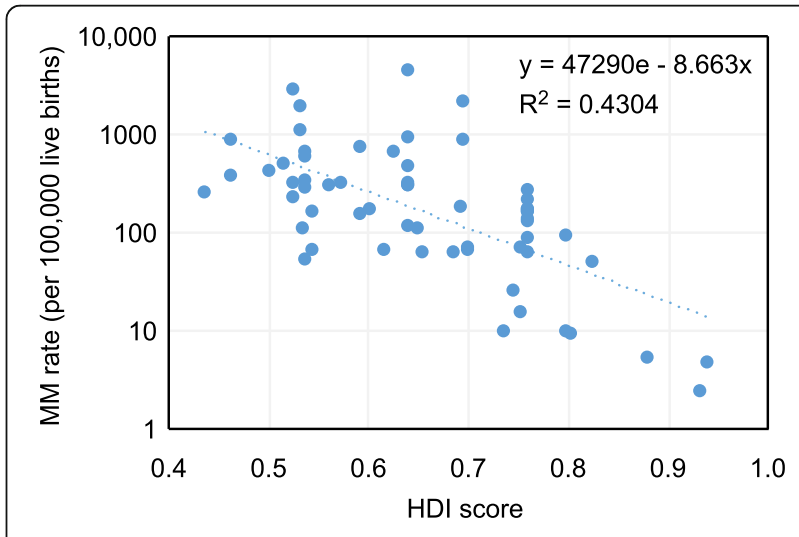

Fig. 3 Relationship between HDI score and MM rate 
Table 2 MNM rate weighted by the number of LBs according to the HDI group

\begin{tabular}{llll}
\hline HDI group & Sum of MNM & Sum of livebirths & MNM rate per 1000 livebirths \\
\hline 1 & 4556 & 1542678 & 2.95 \\
2 & 4844 & 439728 & 11.01 \\
3 & 4265 & 188743 & 22.59 \\
4 & 7196 & 352653 & 20.40 \\
Total & 20861 & 2523802 & 8.26 \\
\hline
\end{tabular}

pregnant women from countries in HDI groups 2 and 3, with proportions of MNM greater than $80 \%$ out of all cases in their respective samples.

Overall, the less common cause of MNM was infection/sepsis, at 7.5\%, although the studies by Rulisa et al. [50] and Benimana et al. [79] observed this cause to be responsible for $30.2 \%$ and $27.6 \%$, respectively, of total MNM cases. Both studies were conducted in countries belonging to HDI group 4. A total of $83.7 \%$ of studies that reported infectious causes of MNM were conducted in countries classified as HDI groups 3 and 4 .

\section{Discussion}

This systematic review of the literature selected eightytwo studies that included over three million live births, over 37,000 MNM cases, and just over 4,000 MM events over the past eleven years, representing over fifty countries.

To our knowledge, this is the most up-to-date review of MNM as an adverse perinatal outcome, and the only one in which the country of origin of the study population has been analysed. In addition, it is the first review that analyses these results in relation to the HDI of each country of publication.

As shown in Table 1, increasingly more studies are publishing MNM results as an indicator for monitoring the quality of maternal health and maternal care. These data will be a valuable contribution to taking necessary action to improve the quality of maternal care.

\section{MNM as an analysis variable of maternal morbidity and} mortality and the importance of the country of origin Despite the differences in MM between countries, these events are increasingly infrequent and related to an LB rate on the order of 100,000 . As stated above, MNM data collection is increasingly necessary; most of the studies included have been published since 2014, showing the growing interest in considering this variable.

Brazil published the most studies in this period, followed by India, Nigeria and Ethiopia; most studies were published in low-HDI countries, leading to publication bias because, as this study shows, cases of severe maternal morbidity are more prevalent in more disadvantaged countries.

As highlighted in Table 1, only four studies underline the relationship between $\mathrm{MNM}$ and migration when analysing maternal origin, where perinatal outcomes were more unfavourable in immigrant groups. However, many studies analysed this variable for MM. In a systematic review that included thirteen studies involving over forty-two million women and 4995 maternal deaths, immigrant women had twice the risk of this complication over native women in Western Europe [92].

As in the results obtained in those four studies regarding both MNM and MM, our results highlight a significant relationship between the HDI of the place of publication and adverse maternal-perinatal outcomes. These results are in line with previous studies by Tuncalp et al. [3] and Luque-Fernandez et al. [5] and those reported previously by our team.

These studies highlight the importance of classifying maternal risk by considering not only economic data but also other relevant aspects of human development and capacity for survival in each country, or, in the case of immigrants, their country of origin, specifically in the case of pregnant women from low-income countries where monitoring of pregnancy and childbirth occurs in their countries of origin and when a pregnant woman

Table $3 \mathrm{MM}$ rate weighted by the number of LBs according to the HDI group

\begin{tabular}{llll}
\hline HDI group & Sum of MM & Sum of livebirths & MM rate per 100,000 live births \\
\hline 1 & 57 & 998443 & 5.7 \\
2 & 527 & 398338 & 132.4 \\
3 & 841 & 188444 & 446.3 \\
4 & 1563 & 277953 & 562.2 \\
Total & 2988 & 1863178 & 160.4 \\
\hline
\end{tabular}



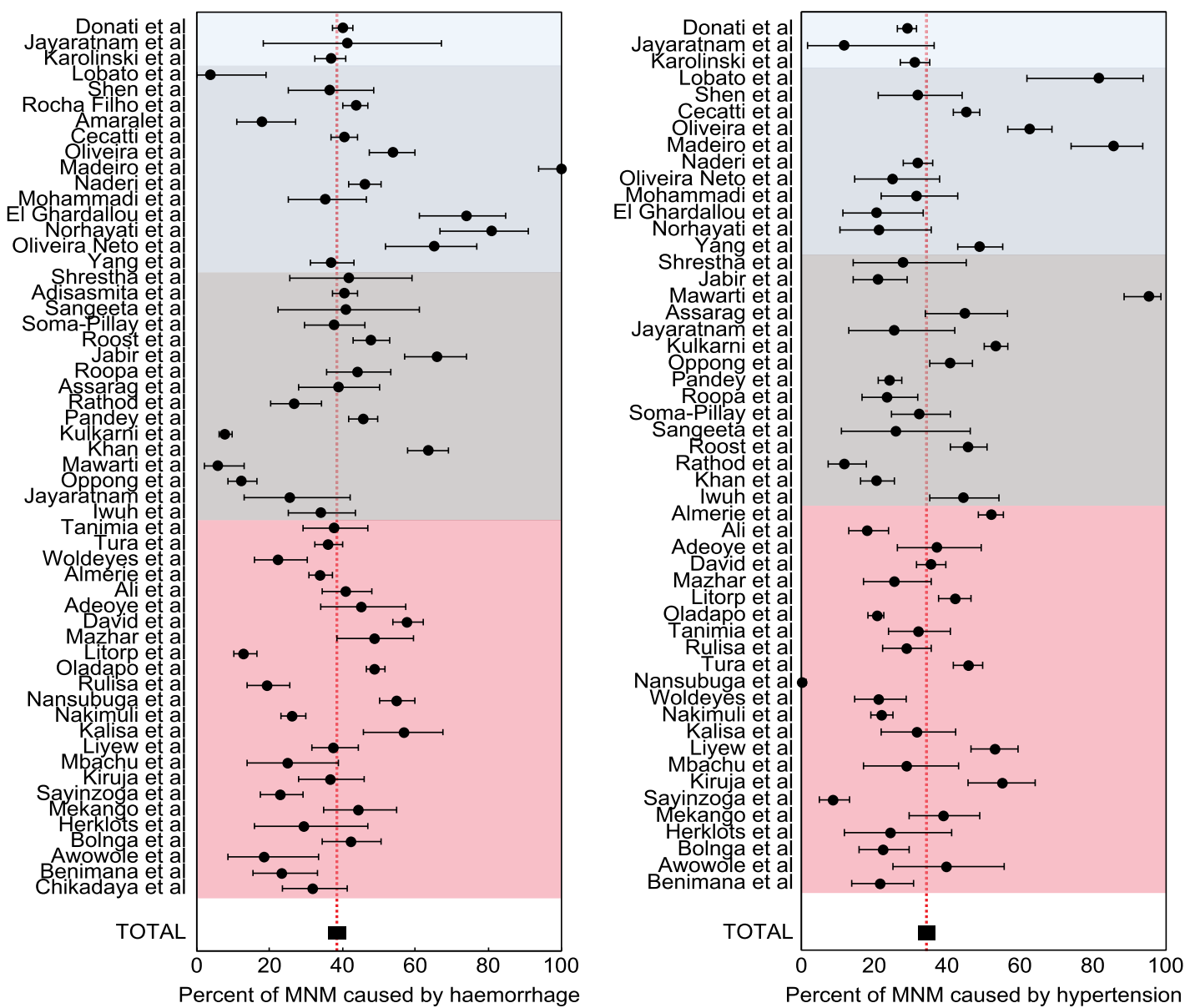

HDI

group:

1

2

3
4

Percent of MNM caused by haemorrhage
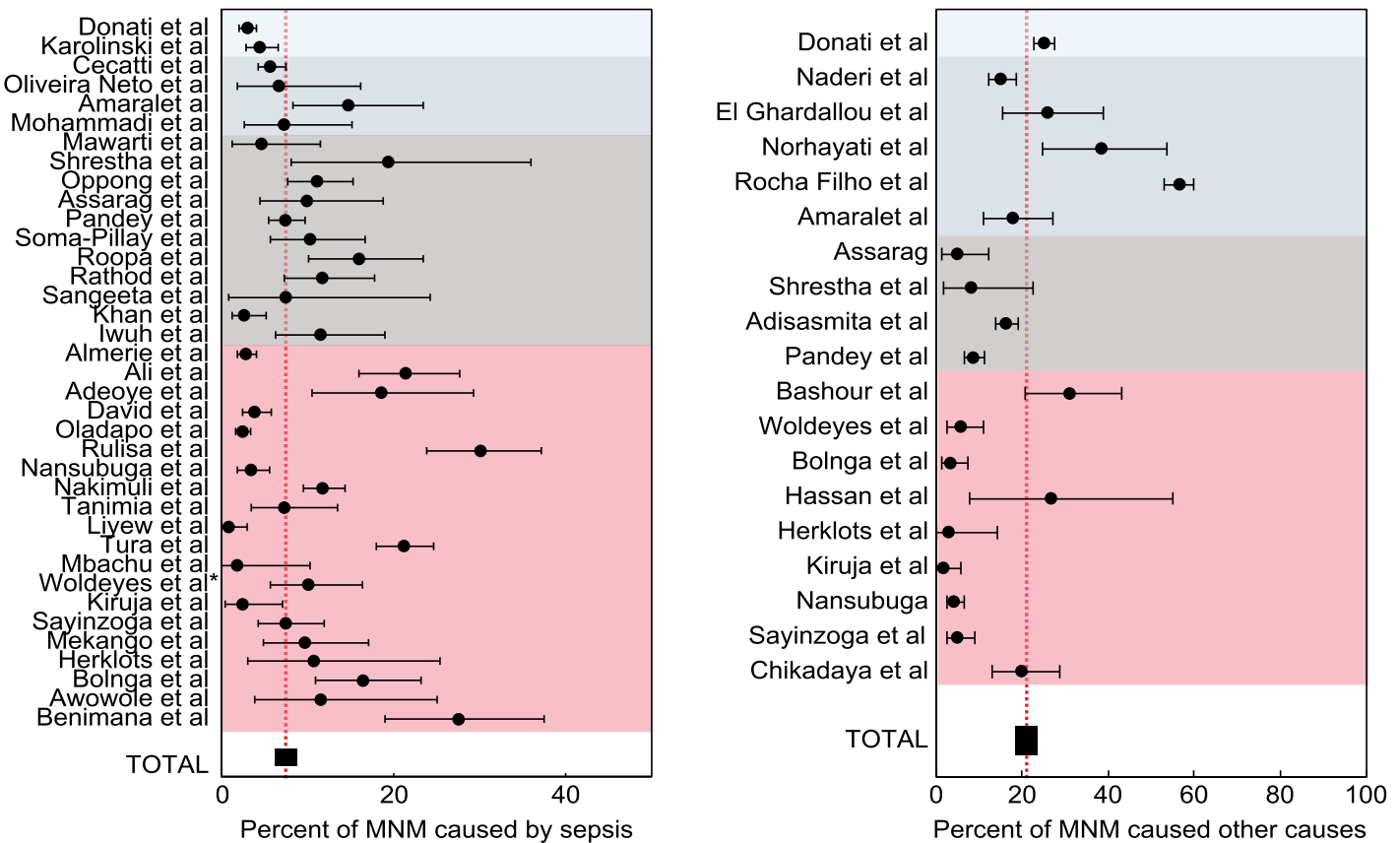

Fig. 4 Proportion of each cause of MNM published according to HDI group 
becomes an immigrant in a country with higher resources. Wahlberg et al. [30] observed, in a study conducted in Sweden that included 914,474 births and 2655 MNM cases, that women from low-income countries had a significant 2.3 times greater risk than native women of suffering from severe morbidity events. This study revealed some hypotheses about plausible mechanisms by which this relationship occurred, such as a breach of previous social networks among immigrant women, low socio-economic status, poor access to health and prenatal care, and communication problems resulting from suboptimal language acquisition.

Urquia et al. [93] analysed 1,252,543 births in Ontario hospitals between 2002 and 2012 and observed heterogeneity that included severe maternal morbidity rates according to the world regions of origin of pregnant women. Overall, they found no significant differences in the risk of such pregnancy complications between native and immigrant women; however, in women from East Asia, such as Vietnam and the Philippines, an increased risk of severe maternal morbidity was observed among these patients in Canadian hospitals.

Finally, it is necessary to highlight the data from Table 1 , which show that only a minority of the authors reported maternal morbidity data, such as MNM, and neonatal morbidity results. Less than $20 \%$ of these publications considered adverse perinatal outcomes in newborns, reporting neonatal mortality as the most common complication but poorly describing very important information such as $\mathrm{pH}$ at birth, Apgar score, need for neonatal resuscitation manoeuvres, or admission to the neonatal intensive care unit.

\section{Main findings}

The present study shows that MNM and MM rates have a significant relationship with maternal country of origin. Specifically, the HDI of the maternal country of origin where the different studies were conducted was significantly related to MNM and MM rates. Thus, we have observed that the lower the HDI score of the maternal country of origin, the greater the risk is of suffering from these 2 severe pregnancy complications.

We must emphasise that HDI group 3 had the highest MNM rate compared to the other groups even though group 4 would be expected to have the worst results for this complication. The reason for this is not explained in our review, although a possible cause could be that HDI group 4 had lower MNM ratios compared to group 3 because cases of severe morbidity in these countries more frequently caused maternal deaths. This hypothesis would explain why HDI group 4 had an overall MM rate higher than Group 3 and other groups.
Thus, the present study allows calculation of the average expected MNM ratios based on the country's HDI score, as shown in the following examples:

- Average MNM rate in Sweden $=331.71 \mathrm{e}^{-4.572 \times 0.933}=4.69$ per $1000 \mathrm{LBs}$
- Average MNM rate in Brazil $=331.71 \mathrm{e}^{-4.572 \times 0.759}=10.38$ per $1000 \mathrm{LBS}$
- Average MNM rate in Uganda $=331.71 \mathrm{e}^{-4.572 \times 0.516}=31.54$ per $1000 \mathrm{LBs}$

In the same way, if we wanted to calculate the average expected MM rate in a country based on its HDI, we could apply the following formula presented in the results section:

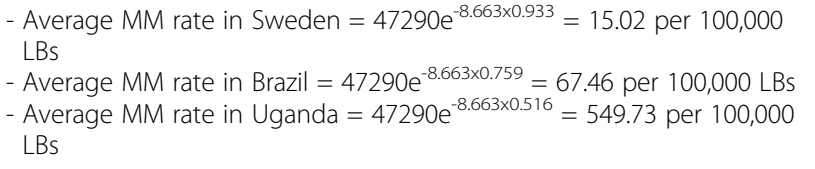

We can observe how the MNM and MM rates increase as the HDI score of the reference country decreases. On the other hand, we see rates of these complications similar to those published by the authors of the studies included in this review. The calculation of these rates is limited by the use of a single explanatory variable such as the HDI score of the country in which the adverse event occurs in the study; therefore, we can observe differences in the results published by other authors, such as the study by Vangen et al. [94] in Norway, which presented an HDI score similar to that of Sweden and a MM rate of 7.2 per 100,000 LBs, half of what was anticipated from our equation.

Estimating these two severe adverse events of pregnancy, childbirth, and the postpartum period can be important for clinicians, enabling them to classify the risk of such events according to the place of maternal origin. Considering previous calculations, a clinician in Sweden can expect that near-miss and mortality rates for a patient attending their hospital from Uganda may be higher than those of a patient from Brazil (if we consider the rates of these countries and how to discriminate between Uganda and Brazil), even if both are immigrants. Obviously, this hypothesis must be confirmed by more studies; surely, the near-miss rate of an immigrant patient in Sweden is lower than that corresponding to their country of origin, but according to our results, it is possible that HDI can help estimate the risk with more accuracy.

The HDI simplifies and captures major sociodemographic characteristics and encompasses various aspects of human development across countries in the form of a common score, as explained above. Therefore, using the HDI, maternal origin can be categorised not only by race and ethnicity but also by income and 
educational level, which provide accurate information regarding poverty and inequality worldwide. According to our systematic review, the excess risk of MNM and MM seems to depend not only on the maternal birthplace but also on the region where the prenatal checkups and delivery took place, other maternal characteristics and the presence of comorbidities. Therefore, taking into account that a significant proportion of MNM and MM cases are avoidable, there should be an initiative to develop and implement epidemiological analysis systems in host countries to identify socio-demographic risk factors - such as indicators of poverty and social impairment that have a significant impact on the perinatal outcomes of pregnant immigrant women.

This proposal to use HDI as a parameter related to morbidity and mortality rates is another step in calculating these risks by analysing other aspects than just the average income of the maternal country of origin or immigrant status. Previously, other authors showed an increased risk of severe maternal morbidity events during pregnancy, childbirth, and the postpartum period in women from low-income countries, such as those in sub-Saharan Africa and the Caribbean [95-97]. The study published by Blagoeva Atanasova et al. [98] in Spain showed a significantly increased MM risk (four times higher) in immigrant women from South American countries. Similarly, this study highlighted important inequalities in the rate of this complication depending on the place of maternal origin.

\section{Near-miss types by HDI group (Figure 4)}

Our review showed that the most common cause of MNM was haemorrhage (38.5\% of cases), followed closely by hypertensive disorders of pregnancy.

Overall, we did not observe significant differences in the proportions of MNM types according to the HDI or maternal HDI groups. Thus, although the absolute number and MNM rate are higher in low-HDI countries compared to countries with higher HDI, the proportion of causes of these maternal morbidity events does not differ substantially from one country to another for reasons that are not clear in the literature.

Published studies reflect heterogeneous results in the proportions of MNM, as in a recent multi-centre analysis published by Oppong et al. [90] conducted in Ghana with $8,433 \mathrm{LBs}$ and $288 \mathrm{MNM}$ cases. In this study, the most common cause of MNM was preeclampsia/eclampsia, at $41 \%$, compared to haemorrhage, which was observed in $12.2 \%$ of cases. The identification and classification of near-miss cases were performed in this group using the WHO Maternal Near Miss Tool [23].

Tanimia et al. [66], however, in a study conducted in Papua New Guinea with 13,338 LBs and 122 near-miss cases, identified, using the same tool and WHO criteria, haemorrhage as the most common cause of maternal near miss $(38 \%)$, followed by hypertensive disorders of pregnancy (32\%).

The main cause of MM identified by the Global Burden of Disease (GBD) study, which conducted a global and regional review of data from 186 countries during the period of 1990-2015, was obstetric haemorrhage. Other relevant causes of MM were hypertensive disorders of pregnancy, maternal sepsis, obstructed labour, and uterine rupture [99].

There are several reasons why the proportion of MNM causes may differ from one study to another even among countries with similar socio-economic development levels as defined by the HDI. On the one hand, the method used in the collection, definition, and classification of MNM varies from one study to another in both the sources and classification systems of these pregnancy complications. There are several cases in which patients may suffer from several types of near-miss incidents, or one cause of near miss may trigger another, but these situations may not be revealed in the results of the studies included in this review. Furthermore, the description of the study population and hospitals where the conditions were treated in the various studies were not always sufficiently detailed to identify the reason why, in some studies, one cause of near miss was more prevalent than another. In this regard, the maternal HDI given by the country of origin where each study was conducted does not explain the differences found between the studies in the proportion of each type of MNM.

\section{Strengths of the review}

This is the most recent and up-to-date systematic review that addresses the importance of characterising pregnant women by their country of origin and investigates a relevant sociodemographic variable, HDI, and its relationship with adverse events such as MNM and MM. From what has been published over the course of a decade, eighty-two articles were collected, describing results from over forty countries, including a large number of patients and maternal morbidity and mortality events.

\section{Limitations of the review}

Several limitations are worth considering when interpreting the results of this review. However, there is a lack of uniform criteria for the identification of cases of severe obstetric morbidity or MNM. The identification of cases is complex and varies across studies. Three major criteria have been mentioned in a review conducted by the WHO [100]. The review suggested the use of organ system dysfunction-based criteria supplemented with compatible clinical markers of organ system dysfunction that are feasible for collection in the absence of higher-level amenitiesbased criteria for identifying all severe morbidity and 
investigating the cause as the most reproducible one across similar areas.

Population characteristics in case-control groups were not always well described; in several studies, relevant adjustment variables of perinatal outcomes were not used, such as maternal comorbidities, maternal age, parity, maternal body mass index (BMI), or belonging to ethnic or sociodemographic groups that are more vulnerable to pregnancy complications.

As we have described, very few studies refer to immigrant pregnant women or maternal HDI influencing adverse events during pregnancy, childbirth, and the postpartum period.

To address these limitations, Mengistu et al. [101] have recently published a protocol for the systematic review and meta-analysis of severe maternal morbidity events and MNM, at least in high-income countries.

Finally, we must note the limitations of the HDI. On the one hand, the population in the study country is not homogeneous with regard to origin, education level, or income; these factors are not always perfectly described in national epidemiological publications or data. On the other hand, migration flows are very diverse from one country to another depending on economic, social, political, and geographical factors; therefore, the quantity and characteristics of the immigrant population of a nation can be more or less heterogeneous even within similar territories, as in the European Union. We attempted to divide the patients into groups in a simple manner that was based on maternal HDI; additionally, we obtained as much information as we could regarding the mothers' social situation, as indicated by their country of origin but this might not be entirely informative.

\section{Conclusions}

In summary, this review of the literature highlights the usefulness of identifying the HDI of the maternal country of origin through the HDI of the country of publication. Based on eighty-two articles, the review includes a great variety of countries, patients, and maternal morbidity and mortality events. This variety has allowed us to study the inverse and significant relationship between maternal morbidity and mortality and the HDI of the countries included. This relationship is maintained according to the HDI groups.

The most common causes of MNM described were haemorrhage and hypertensive disorders of pregnancy and, less frequently, infectious complications and sepsis. Overall, there were no significant differences in the proportion of each cause of MNM, the HDI, and HDI groups.

\section{Implications for clinical practice}

This study shows that the use of maternal sociodemographic variables, including the HDI, may be useful to categorise the risk of maternal morbidity and mortality. In addition to economic value, the HDI weighs education level and life expectancy - as health and social parameters of pregnant women - according to their origin. The HDI is a variable that is easily accessible and calculated, although it may have limitations influenced by other factors, for example, in the immigrant population, such as time spent in the destination country, baseline health state, or the degree of social integration and family income. More studies are needed to determine the discriminatory value of risk in the immigrant population treated in different countries.

\section{Abbreviations}

MM: Maternal mortality; MNM: Maternal near miss; HDI: Human development index; WHO: World Health Organization; GNI: Gross national income; UNDP: United Nations Development Programme; LB: Live births; NR: Non reported; GBD: Global Burden of Disease; BMI: Body mass index

\section{Acknowledgements}

The authors are grateful to Mr Jose María Bellon for statistical assistance.

\section{Authors' contributions}

SGTL and FAV designed the study, reviewed all the studies included and wrote the final manuscript. ICH, EAH and YCL reviewed the final manuscript. $J L L$ designed the study as well and prepared the final manuscript. The author(s) read and approved the final manuscript.

\section{Funding}

No funding was received for this study.

Availability of data and materials

Data from this systematic review is available as supplementary material in table 1 and provided upon request.

\section{Ethics approval and consent to participate}

This is a systematic review of the literature so consent to participate was not required. Ethical approval was not required either.

\section{Consent for publication}

Not Applicable

\section{Competing interests}

The authors declare that they have no competing interests.

\section{Author details}

${ }^{1}$ Maternal Fetal Medicine, Department of Obstetrics and Gynaecology, HGUGM, Calle O' Donnell, 48, Planta 0, 28009 Madrid, Spain. ²Department of Public and Maternal-Infant Health, Complutense University, Madrid, Spain.

Received: 8 September 2019 Accepted: 27 March 2020

Published online: 16 April 2020

References

1. GBD 2015 DALYs and HALE Collaborators. Global, regional, and national disability-adjusted life-years (DALYS) for 315 diseases and injuries and healthy life expectancy (HALE), 1990-2015: a systematic analysis for the global burden of disease study 2015. Lancet. 2016;388:1603-58.

2. Say L, Souza JP, Pattinson RC. Maternal near miss--towards a standard tool for monitoring quality of maternal health care. Best Pract Res Clin Obstet Gynaecol. 2009;23:287-96.

3. Tuncalp O, Hindin MJ, Adu-Bonsaffoh K, Adanu RM. Assessment of maternal near-miss and quality of care in a hospital-based study in Accra, Ghana. Int J Gynaecol Obstet. 2013;123:58-63.

4. Garcia-Tizon Larroca S, Arevalo-Serrano J, Duran Vila A, Pintado Recarte MP, Cueto Hernandez I, Solis Pierna A, et al. Human Development Index (HDI) of the maternal country of origin as a predictor of perinatal outcomes - a longitudinal study conducted in Spain. BMC Pregnancy Childbirth. 2017;17:314. 
5. Luque-Fernandez MA, Thomas A, Gelaye B, Racape J, Sanchez MJ, Williams MA. Secular trends in stillbirth by maternal socioeconomic status in Spain 2007-15: a population-based study of 4 million births. Eur J Pub Health. 2019. https://doi.org/10.1093/eurpub/ckz086.

6. Liberati A, Altman DG, Tetzlaff J, Mulrow C, Gotzsche PC, loannidis JP, et al. The PRISMA statement for reporting systematic reviews and meta-analyses of studies that evaluate health care interventions: explanation and elaboration. PLoS Med. 2009;6:e1000100.

7. Stroup DF, Berlin JA, Morton SC, Olkin I, Williamson GD, Rennie D, et al. Meta-analysis of observational studies in epidemiology: a proposal for reporting. Meta-analysis of Observational Studies in Epidemiology (MOOSE) group. JAMA. 2000;283:2008-12.

8. United Nations Development Programme (UNDP). Summary human development report 2013. New York: United Nations Development Programme (UNDP); 2013.

9. United Nations Development Programme (UNDP). Reports (1990-2013) Human Development Reports (HDR). New York: United Nations Development Programme (UNDP); 2013.

10. Guyatt GH, Oxman AD, Vist GE, Kunz R, Falck-Ytter Y, Alonso-Coello P, et al. GRADE: an emerging consensus on rating quality of evidence and strength of recommendations. BMJ. 2008:336:924-6.

11. Adisasmita A, Deviany PE, Nandiaty F, Stanton C, Ronsmans C. Obstetric near miss and deaths in public and private hospitals in Indonesia. BMC Pregnancy Childbirth. 2008;8:10.

12. Driul L, Cacciaguerra G, Citossi A, Martina MD, Peressini L, Marchesoni D. Prepregnancy body mass index and adverse pregnancy outcomes. Arch Gynecol Obstet. 2008;278:23-6.

13. Roost M, Altamirano VC, Liljestrand J, Essen B. Priorities in emergency obstetric care in Bolivia--maternal mortality and near-miss morbidity in metropolitan La Paz. Bjog. 2009;116:1210-7.

14. Almerie Y, Almerie MQ, Matar HE, Shahrour Y, Al Chamat AA, Abdulsalam A. Obstetric near-miss and maternal mortality in maternity university hospital, Damascus, Syria: a retrospective study. BMC Pregnancy Childbirth. 2010;10:-65.

15. Shrestha NS, Saha R, Karki C. Near miss maternal morbidity and maternal mortality at Kathmandu medical college teaching hospital. Kathmandu Univ Med J (KUMJ). 2010;8:222-6.

16. Souza JP, Cecatti JG, Faundes A, Morais SS, Villar J, Carroli G, et al. Maternal near miss and maternal death in the World Health Organization's 2005 global survey on maternal and perinatal health. Bull World Health Organ. 2010;88:113-9.

17. Ali AA, Khojali A, Okud A, Adam GK, Adam I. Maternal near-miss in a rural hospital in Sudan. BMC Pregnancy Childbirth. 2011;11:48.

18. Amaral E, Souza JP, Surita F, Luz AG, Sousa MH, Cecatti JG, et al. A population-based surveillance study on severe acute maternal morbidity (near-miss) and adverse perinatal outcomes in Campinas, Brazil: the Vigimoma project. BMC Pregnancy Childbirth. 2011;11:9.

19. Donati S, Senatore S, Ronconi A. Obstetric near-miss cases among women admitted to intensive care units in Italy. Acta Obstet Gynecol Scand. 2012; 91:452-7.

20. Jayaratnam S, de Costa C, Howat P. Developing an assessment tool for maternal morbidity 'near-miss'- a prospective study in a large Australian regional hospital. Aust N Z J Obstet Gynaecol. 2011;51:421-5.

21. Kaye DK, Kakaire O, Osinde MO. Maternal morbidity and near-miss mortality among women referred for emergency obstetric care in rural Uganda. Int J Gynaecol Obstet. 2011:114:84-5.

22. Lobato G, Nakamura-Pereira M, Mendes-Silva W, Dias MA, Reichenheim ME. Comparing different diagnostic approaches to severe maternal morbidity and near-miss: a pilot study in a Brazilian tertiary hospital. Eur J Obstet Gynecol Reprod Biol. 2013;167:24-8.

23. Souza JP, Cecatti JG, Haddad SM, Parpinelli MA, Costa ML, Katz L, et al. The WHO maternal near-miss approach and the maternal severity index mode (MSI): tools for assessing the management of severe maternal morbidity. PLoS One. 2012;7:e44129.

24. Adeoye IA, Onayade AA, Fatusi AO. Incidence, determinants and perinatal outcomes of near miss maternal morbidity in Ile-Ife Nigeria: a prospective case control study. BMC Pregnancy Childbirth. 2013;13:93.

25. Jabir M, Abdul-Salam I, Suheil DM, Al-Hilli W, Abul-Hassan S, Al-Zuheiri A, et al. Maternal near miss and quality of maternal health care in Baghdad, Iraq. BMC Pregnancy Childbirth. 2013;13:11.

26. Karolinski A, Mercer R, Micone P, Ocampo C, Mazzoni A, Fontana O, et al. The epidemiology of life-threatening complications associated with reproductive process in public hospitals in Argentina. BJOG. 2013;120: 1685-94.

27. Nelissen EJT, Mduma E, Ersdal HL, Evjen-Olsen B, van Roosmalen JJM, Stekelenburg J. Maternal near miss and mortality in a rural referral hospital in northern Tanzania: a cross-sectional study. BMC Pregnancy Childbirth. 2013;13:141.

28. Roopa PS, Verma S, Rai L, Kumar P, Pai MV, Shetty J. "Near miss" obstetric events and maternal deaths in a tertiary care hospital: an audit. J Pregnancy. 2013;2013:393758.

29. Shen FR, Liu M, Zhang X, Yang W, Chen YG. Factors associated with maternal near-miss morbidity and mortality in Kowloon Hospital, Suzhou, China. Int J Gynaecol Obstet. 2013;123:64-7.

30. Wahlberg A, Roost M, Haglund B, Hogberg U, Essen B. Increased risk of severe maternal morbidity (near-miss) among immigrant women in Sweden: a population register-based study. BJOG. 2013;120:1605-11 discussion 12

31. Abalos E, Cuesta C, Carroli G, Qureshi Z, Widmer M, Vogel JP, et al. Preeclampsia, eclampsia and adverse maternal and perinatal outcomes: a secondary analysis of the world health organization multicountry survey on maternal and Newborn health. BJOG. 2014;121(Suppl 1):14-24.

32. David E, Machungo F, Zanconato G, Cavaliere E, Fiosse S, Sululu C, et al. Maternal near miss and maternal deaths in Mozambique: a cross-sectional, region-wide study of 635 consecutive cases assisted in health facilities of Maputo province. BMC Pregnancy Childbirth. 2014;14:401.

33. Galvao LP, Alvim-Pereira F, de Mendonca CM, Menezes FE, Gois KA, Ribeiro RF Jr, et al. The prevalence of severe maternal morbidity and near miss and associated factors in Sergipe, Northeast Brazil. BMC Pregnancy Childbirth. 2014; 14:25.

34. Litorp H, Kidanto HL, Roost M, Abeid M, Nystrom L, Essen B. Maternal nearmiss and death and their association with caesarean section complications: a cross-sectional study at a university hospital and a regional hospital in Tanzania. BMC Pregnancy Childbirth. 2014;14:244.

35. Luexay P, Malinee L, Pisake L, Marie-Helene BC. Maternal near-miss and mortality in Sayaboury province. Lao PDR BMC Public Health. 2014;14:945.

36. Lumbiganon P, Laopaiboon M, Intarut N, Vogel JP, Souza JP, Gulmezoglu AM, et al. Indirect causes of severe adverse maternal outcomes: a secondary analysis of the WHO multicountry survey on maternal and newborn health. BJOG. 2014;121(Suppl 1):32-9.

37. Mazhar SB, Batool A, Emanuel A, Khan AT, Bhutta S. Severe maternal outcomes and their predictors among Pakistani women in the WHO Multicountry Survey on Maternal and Newborn Health. Int J Gynaecol Obstet. 2015;129:30-3

38. Pacheco AJ, Katz L, Souza AS, de Amorim MM. Factors associated with severe maternal morbidity and near miss in the Sao Francisco Valley, Brazil: a retrospective, cohort study. BMC Pregnancy Childbirth. 2014;14:91.

39. Pandey A, Das V, Agarwal A, Agrawal S, Misra D, Jaiswal N. Evaluation of obstetric near miss and maternal deaths in a tertiary care hospital in north India: shifting focus from mortality to morbidity. J Obstet Gynaecol India. 2014:64:394-9.

40. Rocha Filho EA, Costa ML, Cecatti JG, Parpinelli MA, Haddad SM, Sousa MH, et al. Contribution of antepartum and intrapartum hemorrhage to the burden of maternal near miss and death in a national surveillance study. Acta Obstet Gynecol Scand. 2015;94:50-8.

41. Assarag B, Dujardin B, Delamou A, Meski FZ, de Brouwere V. Determinants of maternal near-miss in Morocco: too late, too far, too sloppy? PLoS One. 2015;10:e0116675.

42. Bashour H, Saad-Haddad G, DeJong J, Ramadan MC, Hassan S, Breebaart M, et al. A cross sectional study of maternal 'near-miss' cases in major public hospitals in Egypt, Lebanon. Palestine and Syria BMC Pregnancy Childbirth. 2015;15:296.

43. Cecatti JG, Souza RT, Pacagnella RC, Leal MC, Moura EC, Santos LM. Maternal near miss among women using the public health system in the Amazon and Northeast regions of Brazil. Rev Panam Salud Publica. 2015;37: 232-8.

44. Hassan SJ, Wick L, DeJong J. A glance into the hidden burden of maternal morbidity and patterns of management in a Palestinian governmental referral hospital. Women Birth. 2015;28:e148-56.

45. Kulkarni R, Chauhan S, Daver R, Nandanwar Y, Patil A, Bhosale A. Prospective observational study of near-miss obstetric events at two tertiary hospitals in Mumbai, Maharashtra. India Int J Gynaecol Obstet. 2016:132:170-3. 
46. Madeiro AP, Rufino AC, Lacerda EZ, Brasil LG. Incidence and determinants of severe maternal morbidity: a transversal study in a referral hospital in Teresina, Piaui, Brazil. BMC Pregnancy Childbirth. 2015;15:210.

47. Naderi T, Foroodnia S, Omidi S, Samadani F, Nakhaee N. Incidence and correlates of maternal near miss in southeast Iran. Int J Reprod Med. 2015; 2015:914713.

48. Oladapo OT, Adetoro OO, Ekele BA, Chama C, Etuk SJ, Aboyeji AP, et al. When getting there is not enough: a nationwide cross-sectional study of 998 maternal deaths and 1451 near-misses in public tertiary hospitals in a low-income country. BJOG. 2016:123:928-38.

49. Oliveira LC, da Costa AA. Maternal near miss in the intensive care unit: clinical and epidemiological aspects. Rev Bras Ter Intensiva. 2015;27:220-7.

50. Rulisa S, Umuziranenge I, Small M, van Roosmalen J. Maternal near miss and mortality in a tertiary care hospital in Rwanda. BMC Pregnancy Childbirth. 2015;15:203.

51. Sangeeta G, Leena W, Taru G, Sushma K, Nupur G, Amrita P. Evaluation of severe maternal outcomes to assess quality of maternal health care at a tertiary center. J Obstet Gynaecol India. 2015;65:23-7.

52. Soma-Pillay P, Pattinson RC, Langa-Mlambo L, Nkosi BS, Macdonald AP. Maternal near miss and maternal death in the Pretoria academic complex, South Africa: a population-based study. S Afr Med J. 2015;105:578-63.

53. Okusanya BO, Sajo AE, Osanyin GE, Okojie OE, Abodunrin ON. Peripartum hysterectomy in a Nigerian university hospital: an assessment of severe maternal outcomes with the maternal severity index model. Niger Postgrad Med J. 2016:23:62-6.

54. de Mucio B, Abalos E, Cuesta C, Carroli G, Serruya S, Giordano D, et al. Maternal near miss and predictive ability of potentially life-threatening conditions at selected maternity hospitals in Latin America. Reprod Health 2016;13:134

55. Domingues RM, Dias MA, Schilithz AO, Leal MD. Factors associated with maternal near miss in childbirth and the postpartum period: findings from the birth in Brazil national survey, 2011-2012. Reprod Health. 2016;13:115.

56. El Ghardallou M, Nabli Ajmi T, Mkhazni A, Zedini C, Meddeb S, Khairi H, et al. Maternal near miss and quality of obstetric care in a Tunisian tertiary level maternity. Afr J Reprod Health. 2016;20:44-50.

57. Jayaratnam S, Burton A, Connan KF, de Costa C. Maternal 'near miss' at Royal Darwin hospital: an analysis of severe maternal morbidity at an Australian regional tertiary maternity unit. Aust N Z J Obstet Gynaecol. 2016; 56:381-6.

58. Kalisa R, Rulisa S, van den Akker T, van Roosmalen J. Maternal Near Miss and quality of care in a rural Rwandan hospital. BMC Pregnancy Childbirth. 2016; 16:324.

59. Lima HM, Carvalho FH, Feitosa FE, Nunes GC. Factors associated with maternal mortality among patients meeting criteria of severe maternal morbidity and near miss. Int J Gynaecol Obstet. 2017;136:337-43.

60. Mohammadi S, Essen B, Fallahian M, Taheripanah R, Saleh Gargari S, Kallestal C. Maternal near-miss at university hospitals with cesarean overuse: an incident case-control study. Acta Obstet Gynecol Scand. 2016;95:777-86.

61. Nakimuli A, Nakubulwa S, Kakaire O, Osinde MO, Mbalinda SN, Nabirye RC, et al. Maternal near misses from two referral hospitals in Uganda: a prospective cohort study on incidence, determinants and prognostic factors. BMC Pregnancy Childbirth. 2016;16:24.

62. Nansubuga E, Ayiga N, Moyer CA. Prevalence of maternal near miss and community-based risk factors in Central Uganda. Int J Gynaecol Obstet. 2016:135:214-20.

63. Norhayati MN, Nik Hazlina NH, Sulaiman Z, Azman MY. Severe maternal morbidity and near misses in tertiary hospitals, Kelantan. Malaysia: a crosssectional study BMC Public Health. 2016;16:229.

64. Parmar NT, Parmar AG, Mazumdar VS. Incidence of maternal "Near-Miss" events in a tertiary care hospital of central Gujarat. India J Obstet Gynaecol India. 2016;66:315-20.

65. Rathod AD, Chavan RP, Bhagat V, Pajai S, Padmawar A, Thool P. Analysis of near-miss and maternal mortality at tertiary referral centre of rural India. J Obstet Gynaecol India. 2016:66:295-300.

66. Tanimia H, Jayaratnam S, Mola GL, Amoa AB, de Costa C. Near-misses at the port moresby general hospital: a descriptive study. Aust N Z J Obstet Gynaecol. 2016;56:148-53.

67. Bolnga JW, Morris M, Totona C, Laman M. Maternal near-misses at a provincial hospital in Papua New Guinea: a prospective observational study. Aust N Z J Obstet Gynaecol. 2017:57:624-9.
68. Goldenberg RL, Saleem S, Ali S, Moore JL, Lokangako A, Tshefu A, et al. Maternal near miss in low-resource areas. Int J Gynaecol Obstet. 2017;138: 347-55.

69. Herklots T, van Acht L, Meguid T, Franx A, Jacod B. Severe maternal morbidity in Zanzibar's referral hospital: measuring the impact of in-hospital care. PLoS One. 2017:12:e0181470.

70. Khan T, Laul P, Laul A, Ramzan M. Prognostic factors of maternal near miss events and maternal deaths in a tertiary healthcare facility in India. Int J Gynaecol Obstet. 2017;138:171-6.

71. Kiruja J, Osman F, Egal JA, Essen B, Klingberg-Allvin M, Erlandsson K. Maternal near-miss and death incidences - frequencies, causes and the referral chain in Somaliland: a pilot study using the WHO near-miss approach. Sex Reprod Healthc. 2017;12:30-6.

72. Liyew EF, Yalew AW, Afework MF, Essen B. Incidence and causes of maternal near-miss in selected hospitals of Addis Ababa. Ethiopia PLoS One. 2017;12:e0179013.

73. Mawarti Y, Utarini A, Hakimi M. Maternal care quality in near miss and maternal mortality in an academic public tertiary hospital in Yogyakarta, Indonesia: a retrospective cohort study. BMC Pregnancy Childbirth. 2017;17:149.

74. Mbachu II, Ezeama C, Osuagwu K, Umeononihu OS, Obiannika C, Ezeama N. A cross sectional study of maternal near miss and mortality at a rural tertiary centre in southern Nigeria. BMC Pregnancy Childbirth. 2017;17:251.

75. Mekango DE, Alemayehu M, Gebregergs GB, Medhanyie AA, Goba G. Determinants of maternal near miss among women in public hospital maternity wards in Northern Ethiopia: a facility based case-control study. PLoS One. 2017;12:e0183886.

76. Sayinzoga F, Bijlmakers L, van der Velden K, van Dillen J. Severe maternal outcomes and quality of care at district hospitals in Rwanda- a multicentre prospective case-control study. BMC Pregnancy Childbirth. 2017;17:394.

77. Witteveen T, Bezstarosti H, de Koning I, Nelissen E, Bloemenkamp KW, van Roosmalen J, et al. Validating the WHO maternal near miss tool: comparing high- and low-resource settings. BMC Pregnancy Childbirth. 2017:17:194

78. Awowole 1O, Omitinde OS, Arogundade FA, Bola-Oyebamiji SB, Adeniyi OA. Pregnancy-related acute kidney injury requiring dialysis as an indicator of severe adverse maternal morbidity at a tertiary center in Southwest Nigeria. Eur J Obstet Gynecol Reprod Biol. 2018;225:205-9.

79. Benimana C, Small M, Rulisa S. Preventability of maternal near miss and mortality in Rwanda: a case series from the university teaching hospital of Kigali (CHUK). PLoS One. 2018;13:e0195711.

80. Chikadaya $H$, Madziyire MG, Munjanja SP. Incidence of maternal near miss in the public health sector of Harare, Zimbabwe: a prospective descriptive study. BMC Pregnancy Childbirth. 2018;18:458.

81. Iwuh IA, Fawcus S, Schoeman L. Maternal near-miss audit in the Metro West maternity service, Cape town, South Africa: a retrospective observational study. S Afr Med J. 2018;108:171-5.

82. Jayaratnam S, Kua S, deCosta C, Franklin R. Maternal 'near miss' collection at an Australian tertiary maternity hospital. BMC Pregnancy Childbirth. 2018;18:221.

83. Liyew EF, Yalew AW, Afework MF, Essén B. Maternal near-miss and the risk of adverse perinatal outcomes: a prospective cohort study in selected public hospitals of Addis Ababa, Ethiopia. BMC Pregnancy Childbirth. 2018; 18:345.

84. Oliveira Neto AF, Parpinelli MA, Costa ML, Souza R, Ribeiro do Valle C, Cecatti JG. Exploring epidemiological aspects, distribution of WHO maternal near Miss Criteria, and organ dysfunction defined by SOFA in cases of severe maternal outcome admitted to obstetric ICU: a cross-sectional study. Biomed Res Int. 2018;2018:5714890.

85. Tura AK, Zwart J, van Roosmalen J, Stekelenburg J, van den Akker T, Scherjon S. Severe maternal outcomes in eastern Ethiopia: application of the adapted maternal near miss tool. PLoS One. 2018;13:e0207350.

86. Woldeyes WS, Asefa D, Muleta G. Incidence and determinants of severe maternal outcome in Jimma university teaching hospital, South-West Ethiopia: a prospective cross-sectional study. BMC Pregnancy Childbirth. 2018;18:255

87. Yang $Y Y$, Fang $Y H$, Wang $X$, Zhang $Y$, Liu XJ, Yin ZZ. A retrospective cohort study of risk factors and pregnancy outcomes in 14,014 Chinese pregnant women. Medicine (Baltimore). 2018:97:e11748.

88. Herklots T, van Acht L, Khamis RS, Meguid T, Franx A, et al. Validity of WHO's near-miss approach in a high maternal mortality setting. PLoS One. 2019;14: e0217135. 
89. Jayaratnam S, Soares M, Jennings B, Thapa AP, Woods C. Maternal mortality and 'near miss' morbidity at a tertiary hospital in Timor-Leste. Aust N Z Obstet Gynaecol. 2019;59:567-72.

90. Oppong SA, Bakari A, Bell AJ, Bockarie Y, Adu JA, Turpin CA, et al. Incidence, causes and correlates of maternal near-miss morbidity: a multi-centre crosssectional study. BJOG. 2019;126:755-62.

91. Zanardi DM, Parpinelli MA, Haddad SM, Costa ML, Sousa MH, Leite DFB, et al. Adverse perinatal outcomes are associated with severe maternal morbidity and mortality: evidence from a national multicentre crosssectional study. Arch Gynecol Obstet. 2019;299:645-54.

92. Pedersen GS, Grontved A, Mortensen LH, Andersen AM, Rich-Edwards J. Maternal mortality among migrants in Western Europe: a meta-analysis. Matern Child Health J. 2014;18:1628-38.

93. Urquia ML, Wanigaratne S, Ray JG, Joseph KS. Severe maternal morbidity associated with maternal birthplace: a population-based register study. J Obstet Gynaecol Can. 2017;39:978-87.

94. Vangen S, Bodker B, Ellingsen L, Saltvedt S, Gissler M, Geirsson RT, et al. Maternal deaths in the Nordic countries. Acta Obstet Gynecol Scand. 2017; 96:1112-9

95. Knight M, Kurinczuk JJ, Spark P, Brocklehurst P. Inequalities in maternal health: national cohort study of ethnic variation in severe maternal morbidities. BMJ. 2009:338:b542.

96. Urquia ML, Glazier RH, Mortensen L, Nybo-Andersen AM, Small R, Davey MA, et al. Severe maternal morbidity associated with maternal birthplace in three high-immigration settings. Eur J Pub Health. 2015;25:620-5.

97. Zwart JJ, Jonkers MD, Richters A, Ory F, Bloemenkamp KW, Duvekot JJ, et al. Ethnic disparity in severe acute maternal morbidity: a nationwide cohort study in the Netherlands. Eur J Pub Health. 2011;21:229-34.

98. Blagoeva Atanasova V, Arevalo-Serrano J, Antolin Alvarado E, Garcia-Tizon LS Maternal mortality in Spain and its association with country of origin: crosssectional study during the period 1999-2015. BMC Public Health. 2018;18:1171.

99. GBD 2015 Maternal Mortality Collaborators. Global, regional, and national levels of maternal mortality, 1990-2015: a systematic analysis for the global burden of disease study 2015. Lancet. 2016;388:1775-812.

100. Chhabra P. Maternal near miss: an indicator for maternal health and maternal care. Indian J Community Med. 2014;39:132-7.

101. Mengistu TS, Turner J, Flatley C, Fox J, Kumar S. Impact of severe maternal morbidity on adverse perinatal outcomes in high-income countries: systematic review and meta-analysis protocol. BMJ Open. 2019;9:e027100.

\section{Publisher's Note}

Springer Nature remains neutral with regard to jurisdictional claims in published maps and institutional affiliations.

Ready to submit your research? Choose BMC and benefit from:

- fast, convenient online submission

- thorough peer review by experienced researchers in your field

- rapid publication on acceptance

- support for research data, including large and complex data types

- gold Open Access which fosters wider collaboration and increased citations

- maximum visibility for your research: over $100 \mathrm{M}$ website views per year

At $\mathrm{BMC}$, research is always in progress.

Learn more biomedcentral.com/submissions 